\title{
Evaluation of Dip Angles of Active Faults Beneath the Osaka Plain Inferred from a 2D Numerical Analysis of visco-elasto-plastic Models
}

\section{Hayami Nishiwaki}

Osaka City University: Osaka Shiritsu Daigaku

Takamoto Okudaira ( $\square$ oku@sci.osaka-cu.ac.jp)

Osaka City University: Osaka Shiritsu Daigaku https://orcid.org/0000-0002-6695-6246

\section{Kazuhiko Ishii}

Osaka Prefecture University

\section{Muneki Mitamura}

Osaka City University: Osaka Shiritsu Daigaku

\section{Full paper}

Keywords: dip angle, fault geometry, visco-elasto-plastic simulation, Uemachi fault zone, Ikoma fault zone, Osaka Group, Osaka Plain, 2018 northern Osaka earthquake, active fault, seismogenic source fault

Posted Date: September 24th, 2020

DOl: https://doi.org/10.21203/rs.3.rs-79376/v1

License: (9) This work is licensed under a Creative Commons Attribution 4.0 International License. Read Full License 
1 Evaluation of dip angles of active faults beneath the Osaka Plain inferred from a

2 2D numerical analysis of visco-elasto-plastic models

3

4 Hayami Nishiwaki, Department of Geosciences, Osaka City University, Osaka 558-

5 8585, Japan, m19sco19@jr.osaka-cu.ac.jp

6 Takamoto Okudaira, Department of Geosciences, Osaka City University, Osaka 558-

7 8585, Japan, oku@sci.osaka-cu.ac.jp, ORCID iD: 00oo-00o2-6695-6246

8 Kazuhiko Ishii, Department of Physical Sciences, Osaka Prefecture University, Sakai

9 599-8531, Japan, ishii@p.s.osakafu-u.ac.jp, ORCID iD: 00oo-0002-4172-1248

10 Muneki Mitamura, Department of Geosciences, Osaka City University, Osaka 558-

11 8585, Japan, mitamura@sci.osaka-cu.ac.jp, ORCID iD: 0000-0002-6875-439X

12

13 Correspondence: Nishiwaki H, Okudaira T 


\section{Abstract}

16 The geometries (i.e., dip angles) of active faults from the surface to the seismogenic

17 zone are among the most important factors used to evaluate earthquake ground motion,

18 which is crucial to seismic hazard assessments in urban areas. In Osaka, a metropolitan

19 city in Japan, there are several active faults (e.g., the Uemachi and Ikoma faults), which

20 are inferred from the topography, the attitude of active faults in surface trenches, the

21 seismic reflection profile at shallow depths (less than $2 \mathrm{~km}$ ), and the three-dimensional

22 distribution of the Quaternary sedimentary layers. The Uemachi and Ikoma faults are

$23 \mathrm{~N}-\mathrm{S}$-striking fault systems with total lengths of $42 \mathrm{~km}$ and $38 \mathrm{~km}$, respectively, with the

24 former being located $\sim 12 \mathrm{~km}$ west of the latter; however, the geometries of each of the

active faults within the seismogenic zone is not clear. In this study, to examine the

26 geometries of the Uemachi and Ikoma faults from the surface to the seismogenic zone,

we analyze the development of the geological structures of sedimentary layers based on

numerical simulations of a two-dimensional visco-elasto-plastic body under a horizontal

compressive stress field, including preexisting linear high-strained weak zones (i.e.,

30 faults) and surface sedimentation processes, and evaluate the relationship between the 
observed geological structures of the Quaternary sediments (i.e., the Osaka Group) in

32 the Osaka Plain and the model results. Based on a comparison between the simulation

33 results and the geological observations/interpretation, we propose geometries of the

34 Uemachi and Ikoma faults from the surface to the seismogenic zone. When the friction

35 coefficient of the faults is $\sim 0.5$, the dip angles of the Uemachi and Ikoma faults near the

36 surface are $\sim 30^{\circ}-40^{\circ}$ and the Uemachi fault has a downward convex curve at the

37 bottom of the seismogenic zone but does not converge to the Ikoma fault. Based on the

38 analysis in this study, the dip angle of the Uemachi fault zone is estimated to be

39 approximately $30^{\circ}-40^{\circ}$, and the downward extension of the Uemachi fault zone nearly

40 coincides with the epicenter of the 2018 northern Osaka earthquake.

41

42 Keywords: dip angle, fault geometry, visco-elasto-plastic simulation, Uemachi fault

43 zone, Ikoma fault zone, Osaka Group, Osaka Plain, 2018 northern Osaka earthquake,

44 active fault, seismogenic source fault 
47 The 2018 northern Osaka earthquake that occurred on June 18, 2018, was located at the

48 junction of the Arima-Takatsuki fault zone and the Ikoma fault zone. The focal

49 mechanism solution for this earthquake showed a $\mathrm{N}-\mathrm{S}$-striking reverse fault type (Kato

50 and Ueda 2019). If the dip angle of the Uemachi fault zone, which is a reverse fault with

51 a N-S strike and E dip, is approximately $40^{\circ}$, the downward extension of the Uemachi

52 fault zone would nearly coincide with the epicenter of the earthquake (Fig. 1). However,

53 the relationship between this earthquake and the Uemachi fault zone is still unknown

54 because the attitude (i.e., the strike and dip angle) of the Uemachi fault zone at the depth

55 of the seismogenic zone is not well understood. Similar to the Uemachi fault zone, the

56 attitude of active faults, including the Ikoma fault zone, in the Osaka Plain within the

57 seismogenic zone (at a depth of $\sim 10-15 \mathrm{~km}$ ) is not clear. The topography, the attitudes

58 of active faults in surface trenches, seismic reflection profiles at shallow depths (less

59 than $2 \mathrm{~km}$ ), and the three-dimensional distribution of the Quaternary strata based on

60 bored geological columns have been used by the Headquarters for Earthquake Research

61 Promotion of MEXT and the Central Disaster Prevention Council to evaluate the

62 activities of each active fault. The deep underground attitudes of active faults have been 
63 estimated assuming that the attitude near the surface hardly changes with depth (e.g.,

64 Headquarters for Earthquake Research Promotion of MEXT 2001, 2004; Director

65 General for Disaster Management 2006; Fig. 1). To mitigate earthquake damage, it is

66 essential to predict ground motion caused by earthquakes that occur on active faults,

67 and the attitude of the source fault in the seismogenic zone is the most important factor

68 used to predict the ground motion.

69 To estimate the dip angles of the active faults at depth in the Osaka Plain, numerical

70 analyses were performed to determine how the deformation of the strata and the ground

71 surface changes as a result of different fault dip angles; the simulation results can be

72 compared to the distribution of the strata in the Osaka Group and the inclination angle

73 of the axial plane of the subsurface flexure of the Uemachi fault (Ishiyama 2003;

74 Iwasaki 2016; Fig. 1). However, these different dip angles were obtained by forcibly

75 deforming the pre-deposited strata via displacement at the fault; factors, such as the

76 fault behavior under the assumed stress field, the rheological properties of the rocks and

77 sediments, and sedimentation and erosion, have not been considered.

78 In this study, to examine the geometries of the Uemachi and Ikoma faults at the depth 
79 of the seismogenic zone, we analyze the development of geological structures in the

80 sedimentary layers based on numerical simulations of a two-dimensional

81 visco-elasto-plastic body under a horizontal compressive stress field, including

82 preexisting linear high-strained weak zones (i.e., faults) and surface sedimentation

83 processes, and evaluate the relationship between the observed geological structures of

84 the Quaternary sediments (i.e., the Osaka Group) in the Osaka Plain and the model

85 results.

86

87 Constraints on the numerical simulation: Quaternary geology in the Osaka Plain

88 The Osaka sedimentary basin is an oval topographical depression surrounded by

89 mountains, and the Osaka Bay and the Osaka Plain are located in its western and eastern

90 regions, respectively. The boundary between the Osaka Plain and the surrounding

91 mountains is demarcated to the north by the ENE-WSW-trending Arima-Takatsuki fault

92 zone and to the east by the $\mathrm{N}-\mathrm{S}$-trending Ikoma fault zone. The $\mathrm{N}-\mathrm{S}$-trending Uemachi

93 fault zone is located in the central part of the Osaka Plain (Fig. 2a). Quaternary crustal

94 deformation in and around the Osaka sedimentary basin is referred to as the Rokko 
movements (Ikebe and Huzita 1966; Huzita 1968, 1990) and result from the subduction

96 of the Pacific Plate at the Japan Trench and that of the Philippine Sea Plate at the

97 Nankai Trough (Huzita 1968; Itoh et al. 2000). Based on a comparison between the

98 present stress conditions, the direction of the horizontal maximum stress $\left(\sigma \mathrm{H}_{\max }\right)$ is

99 currently nearly E-W (Tsukahara and Kobayashi 1991; Terakawa and Matsu'ura 2010),

100 and the conditions determined by inverting the fault-slip data from active faults that

101 have exhibited cumulative displacement for the past $\sim 10^{5}$ years, it has been suggested

102 that the stress field in central Japan has been uniform and stable for the past $\sim 10^{5}$ years

103 (Tsutsumi et al. 2012). Wesnousky et al. (1982) estimated the geological horizontal

104 shortening strain rate of central Japan, including in the Kinki region, to be $16-26 \times$

$10510^{-9} / \mathrm{yr}$, based on earthquake records with a magnitude of 6.9 or greater and the

106 displacement rates of active faults for the last $\sim 400$ years. We first summarize the

107 Quaternary geology in the Osaka Plain, especially that of the Osaka Group, Uemachi

108 fault zone, and Ikoma fault zone, because the geometry in these regions constrains the

109 model parameters and results. 
112 The Osaka sedimentary basin is filled by the strata of the Plio-Middle Pleistocene

113 Osaka Group, Middle-Upper Pleistocene terrace deposits and their corresponding

114 sediments, and Upper Pleistocene-Holocene alluvium. The strata are 1,000-2,000-m

115 thick at the deposition center and 200-400-m thick at the margins (Itihara 1993).

116 Yoshikawa and Mitamura (1999) reported that the Quaternary system in the Osaka Plain

117 consists of unconsolidated clay, silt, sand, and gravel layers with a thickness of more

118 than $1,500 \mathrm{~m}$ and dozens of volcanic ash layers; this system has been divided into the

119 Miyakojima Formation in the lower part, the Tanaka Formation in the upper part, and

120 the Namba Formation in the uppermost part (Fig. 2b). The Miyakojima Formation

121 consists of freshwater layers primarily composed of gravel, sand, and silt layers,

122 whereas the Tanaka and Namba formations consist of freshwater sand and gravel layers

123 and 21 marine clay layers (Ma-1, Ma0, Ma0.5, Ma1, Ma1.3, Ma1.5, Ma1.7, Ma2,...,

124 Ma11 (1), Ma11 (2), Ma12, and Ma13).

125 Since the 1995 Hyogoken-Nambu earthquake, multiple drilling and seismic

126 reflection surveys have been conducted in the Osaka Plain, revealing details concerning 
127 its subsurface structure. Ikebe et al. (1970) analyzed nine deep drilling cores (OD-1-

128 OD-9) and found that the Osaka Plain can be divided into two areas (i.e., west and east

129 Osaka) by the $\mathrm{N}-\mathrm{S}$-trending Uemachi fault zone running through the central part of the

130 plain. The basement depth in west Osaka is more than 1,000 $\mathrm{m}$ (because the OD-1 core

131 did not reach basement rock at a depth of $907 \mathrm{~m}$ ), whereas the basement depth in the

132 Uemachi Upland and its northern extension is as shallow as $656 \mathrm{~m}$ (OD-2; Fig. 2b). The

133 basement depth in the central part of the Osaka Plain was examined based on the

134 basement structures inferred from gravity anomalies (Nakagawa et al. 1996a; Kansai

135 Geo-informatics Council 1998) and reflection seismic surveys (Ikebe et al. 1970). Using

136 this information, Uchiyama et al. (2001) and the Osaka Prefecture (2004) found that the

137 depth of the basement surface in west Osaka is nearly $1,500 \mathrm{~m}$ and does not

138 significantly change to the west; meanwhile, in east Osaka, the depth is approximately

$139800 \mathrm{~m}$ near the Uemachi Upland and more than 1,500 m near the Onchi River and the

140 surface of the basement slopes to the east (Fig. 3). In addition, the strata thickness does

141 not change in west Osaka, whereas the strata thickness in east Osaka tends to increase

142 eastward (Uchiyama et al. 2001). In detail, in east Osaka, the thickness of the 
143 Miyakojima Formation is approximately $550 \mathrm{~m}$ at the Uemachi Upland and more than

144700 m near the Onchi River and the thickness of the lower Tanaka Formation (Ma-1-

145 Ma6) is approximately $250 \mathrm{~m}$ at the Uemachi Upland and $850 \mathrm{~m}$ near the Onchi River.

146 According to Uchiyama et al. (2001), the sedimentation rate from $\sim 1.2$ million to

$147 \sim 0.05$ million years ago (Ma) in west Osaka, obtained from the OD-1 core, gradually

148 decreased from $0.7 \mathrm{~m} / \mathrm{kyr}$ to $0.2 \mathrm{~m} / \mathrm{kyr}$ and the rate of the decrease in the sedimentation

149 rate was higher after $\sim 0.4 \mathrm{Ma}$. In east Osaka, in the western region near the Uemachi

150 Upland (OD-2, OD-9, and YU), the sedimentation rate from $\sim 1.2 \mathrm{Ma}$ to $0.6 \mathrm{Ma}$,

151 corresponding to the lower Tanaka Formation, decreases from $0.5 \mathrm{~m} / \mathrm{kyr}$ to $0.3 \mathrm{~m} / \mathrm{kyr}$,

152 whereas the sedimentation rate decreases from $0.8 \mathrm{~m} / \mathrm{kyr}$ to $0.5 \mathrm{~m} / \mathrm{kyr}$ in the eastern

153 region (OD-3). The Tanaka Formation around the Uemachi Upland is preserved in

154 conformity only from the Ma3 layer to the Ma7 layer and is partially covered in an

155 unconformity by the Ma12 layer. Suzuki (2016) estimated the sedimentation rate of the

156 Miyakojima Formation to be $0.48 \mathrm{~m} / \mathrm{kyr}$ using the deep drilling core data of Yoshikawa

157 et al. (2000). 
160 The Uemachi fault zone is a nearly N-S-striking fault system with a total length of 42

$161 \mathrm{~km}$, including the Butsunenji-yama fault, Uemachi fault, Nagai fault, Sakamoto fault,

162 Kumedaike fault, Sakuragawa flexure, and Suminoe flexure. It is a reverse fault in

163 which the eastern side of the fault zone has moved upward relative to the western side

164 (Nakada et al. 1996a, 1996b, 1996c, 1996d; Okada and Togo 2000). It has been

165 confirmed that the Uemachi fault zone has cut up to the Ma12 layer (Mitamura et al.

166 1994) and that the Holocene sediments near the surface are bent (Headquarters for

167 Earthquake Research Promotion of MEXT 2004). The dip angle of the fault has been

168 estimated to be $65^{\circ}-70^{\circ}$ (Headquarters for Earthquake Research Promotion of MEXT

169 2004), as inferred from topographical and geological features (Huzita and Kasama

170 1982) and the results of seismic reflection surveys (e.g., Sugiyama and Sangawa 1996;

171 Sugiyama, 1997; Sugiyama et al. 2001, 2003). Based on the difference in the thickness

172 of the Quaternary strata between the eastern and western sides of the Uemachi fault, the

173 displacement rate of the Uemachi fault zone from 1.2 Ma to 0.6 Ma has been estimated

174 to be $\sim 0.3 \mathrm{~m} / \mathrm{kyr}$ (Uchiyama et al. 2001) while that from 0.6 Ma to $0.15 \mathrm{Ma}$ has been 
175 estimated to be $\sim 0.4 \mathrm{~m} / \mathrm{kyr}$ (Headquarters for Earthquake Research Promotion of

176 MEXT 2001).

177 Ishiyama (2003), based on the seismic reflection survey of Yoshikawa et al. (1987),

178 interpreted the bending structure of the reflection section as a fault-propagation fold.

179 Given that the Uemachi fault has a dip angle of $\sim 40^{\circ}$ and that there is $1 \mathrm{~km}$ of slip along

180 the fault, he demonstrated, using the trishear fault-propagation fold model of

181 Allmendinger (1998), that the sedimentary structure of the Ma-1 layer at the lowermost

182 part of the Tanaka Formation can be reproduced. Furthermore, because the Osaka Group

183 is thinner at the Uemachi Upland and thicker eastward, Ishiyama (2003) suggested that

184 the Uemachi fault zone may be a thin-skinned thrust converging to a low-angle

185 detachment in the upper crust (less than $5 \mathrm{~km}$; Fig. 1). Sato et al. (2009) interpreted the

186 seismic reflection results to indicate that the Uemachi and Ikoma fault zones inclined to

187 the east and that their low-angle detachment faults converge at a depth of approximately

$18810 \mathrm{~km}$, which is much deeper than the depth suggested by Ishiyama (2003). Iwasaki

189 (2016) evaluated the dip angle of the Uemachi fault using PLAXIS ${ }^{\circledR}$, a finite element

190 method ground analysis software. Given a displacement of several meters along the 
191 fault with a dip angle of $\sim 30^{\circ}$ and with the fault tip located $1,000 \mathrm{~m}$ below the surface,

192 the inclination angle of the axial plane of the Sakuragawa flexure $\left(65^{\circ}-70^{\circ}\right)$ can be 193 reproduced.

\section{Ikoma fault zone}

196 The Ikoma fault zone is a nearly N-S-striking fault system with a total length of $38 \mathrm{~km}$.

197 It is composed of the Ikoma fault, Katano fault, Hirakata fault, Taguchi fault, and Konda

198 fault (Nakada et al. 1996a, 1996b; Okada et al. 1996; Shimokawa et al. 1997; Sugiyama

199 et al. 1999; Okada and Togo 2000). At the surface, the Ikoma fault is located $\sim 12 \mathrm{~km}$

200 east of the Uemachi fault (Fig. 2a) The Ikoma fault is an east-side-up reverse fault

201 located near the boundary between the Osaka Plain and the Ikoma Mountains, which

202 consist of rocks of the Ryoke belt (Horike et al. 1995; Nakata et al. 1996a, 1996b;

203 Shimokawa et al. 1997). Active faults are inferred from the fact that the low fault cliff

204 that cuts the lower terrace runs alongside the Ikoma fault approximately $0.5-1 \mathrm{~km}$ to its

205 west, with the location of the fault estimated along the slope transformation line that

206 transitions from the mountain slope to the fan; the inferred active faults are thought to 
207 be more important in the Holocene than the fault along the mountain slope (Okada and

208 Yagi 2019; Okada and Togo 2000). Using seismic reflection surveys at the Ikoma fault,

209 Shimokawa et al. (1997) found that the Ikoma fault is inclined to the east at a moderate

210 angle (approximately $30^{\circ}-40^{\circ}$ ) below a depth of $400 \mathrm{~m}$. Furthermore, they estimated the

211 mean vertical displacement rate of the Ikoma fault system to be $0.5-1 \mathrm{~m} / \mathrm{kyr}$, as inferred

212 from a trench survey. Ishiyama (2003) suggested that the high uplift rate of the Ikoma

213 fault zone indicates thick-skinned trajectories. He also pointed out that the downward

214 projection of the Uemachi fault zone soles into the Ikoma fault in the shallower portion

215 of the crust, suggesting that the northern Uemachi fault zone and the Ikoma fault zone

216 comprise a larger system of a west-verging active fold and thrust belt that

217 accommodates E-W contraction within the upper crust and that the Uemachi fault zone

218 is a leading edge of the thrust belt.

219

220 Numerical simulations

$221 \quad$ Method

222 Numerical simulations of a two-dimensional visco-elasto-plastic body were performed 
$224 \mathrm{MATLAB}^{\circledR}$, with the deviatoric strain rate, $\dot{\varepsilon}_{i j}$, including three components:

225

226

$$
\dot{\varepsilon}_{i j}=\dot{\varepsilon}_{i j(\text { viscous })}+\dot{\varepsilon}_{i j(\text { elastic })}+\dot{\varepsilon}_{i j \text { (plastic) }} \text {, }
$$

227

228 where

229

$230 \quad \dot{\varepsilon}_{i j(\text { viscous })}=\frac{1}{2 \eta} \sigma_{i j}$,

231

$232 \quad \dot{\varepsilon}_{i j(\text { elastic })}=\frac{1}{2 G} \frac{\mathrm{D} \sigma_{i j}}{\mathrm{D} t}$

233

$234 \dot{\varepsilon}_{i j \text { (plastic) }}=0$ for $\sigma_{\text {II }}<\sigma_{\text {yield }}$,

$235 \dot{\varepsilon}_{i j(\text { plastic })}=\chi \frac{\sigma_{i j}}{2 \sigma_{\mathrm{II}}}$ for $\sigma_{\mathrm{II}}=\sigma_{\text {yield }}$,

236

237 where $\eta$ is the effective viscosity, $G$ is the shear modulus, $\mathrm{D} \sigma_{i j} / \mathrm{D} t$ is the objective

238 co-rotational time derivative of the deviatoric stress component $\sigma_{i j}$, $\sigma_{\text {yield }}$ is the plastic 
239 yield strength for a given rock, $\sigma_{\mathrm{II}}=\left(1 / 2 \sigma_{i j} \sigma_{i j}\right)^{1 / 2}$ is the second deviatoric stress invariant,

240 and $\chi$ is the plastic multiplier.

241 To yield an effective rheology, the Mohr-Coulomb law was simplified using the

242 yield stress, $\sigma_{\text {yield }}$, criterion and implemented using a "Mohr-Coulomb viscosity", $\eta_{M C}$,

243 as follows:

244

$245 \quad \eta_{\mathrm{MC}}=\sigma_{\text {yield }} /\left(2 \dot{\varepsilon}_{\text {II }}\right)$,

247 where $\dot{\varepsilon}_{\mathrm{II}}=\left(1 / 2 \dot{\varepsilon}_{i j} \dot{\varepsilon}_{i j}\right)^{1 / 2}$ is the second invariant of the strain rate tensor. The yield

248 stress or plastic strength, $\sigma_{\text {yield }}$, of a rock generally depends on the mean stress on the

249 solids, $P$, such that

250

251

$$
\sigma_{\text {yield }}=C+\sin (\varphi) P
$$

252

253 where $C$ is the cohesion (the residual strength at pressure $P=0$ ) and $\varphi$ is the effective

254 internal friction angle. The effective viscosity, $\eta$, is then defined using the following 
criterion:

256

$257 \quad \eta=\eta_{\text {creep }}$, when $2 \dot{\varepsilon}_{\text {II }} \eta_{\text {creep }}<\sigma_{\text {yield }}$,

$258 \eta \eta=\eta_{M C}$, when $2 \dot{\varepsilon}_{\text {II }} \eta_{\text {creep }}>\sigma_{\text {yield }}$,

260 where $\eta_{\text {creep }}$ is the creep viscosity. The creep viscosity, depending on the stress and

261 temperature, is defined by the following power law equation:

262

263

$$
\eta_{\text {creep }}=1 / 2 \dot{\varepsilon}_{\text {II }}^{(1-n) / n} A^{-1 / n} \exp (E / n R T)
$$

265 where $A$ is the pre-exponential factor $\left[/\left(\mathrm{Pa}^{n} \cdot \mathrm{s}\right)\right], E$ is the activation energy $[\mathrm{J} / \mathrm{mol}], n$ is

266 the stress exponent, $T$ is the temperature $[\mathrm{K}]$, and $R$ is the gas constant $(8.314$

$267 \mathrm{~J} /(\mathrm{K} \cdot \mathrm{mol}))$.

268 In this study, for the sediment layer and the upper basement layer (i.e., the upper

269 crust), we used the flow law parameters for wet quartz $\left(A=4.0 \times 10^{-11.2} /\left(\mathrm{MPa}^{n} \cdot \mathrm{s}\right)\right.$,

270 including the effect of a constant water fugacity of $4 \mathrm{MPa}$ at $T=473 \mathrm{~K}$ and $P=200$ 
$271 \mathrm{MPa}, n=4$, and $E=135 \mathrm{~kJ} / \mathrm{mol}$; Hirth et al. 2001), and for the lower basement layer

272 (i.e., the lower crust), we used the flow law parameters for wet plagioclase $\left(\mathrm{An}_{60}\right)(A=$

$2731.0 \times 10^{-1.5} /\left(\mathrm{MPa}^{n} \cdot \mathrm{s}\right), n=3$, and $E=235 \mathrm{~kJ} / \mathrm{mol}$; Rybacki and Dresen 2004). To

274 incorporate the effect of strain weakening, it is modelled as a linear decrease of friction

275 angle and cohesion between accumulated strain of $\varepsilon_{\mathrm{II}}=0$ and $\varepsilon_{\mathrm{II}}=1$. These lower and

276 upper thresholds of strain for weakening activation and completion are similar to those

277 in previous numerical investigations of strain weakening of crustal rocks (e.g., Allken et

278 al 2012; Ruh et al. 2014; Döhmann et al. 2019). At $\varepsilon_{I I}<1$, the cohesion and friction

279 angle change linearly from the initial cohesion $\left(C_{i}\right)$ and initial friction angle $\left(\varphi_{i}\right)$ to the

280 weakened cohesion $\left(C_{w}\right)$ and weakened friction angle $\left(\varphi_{w}\right)$, respectively, whereas at $\varepsilon_{\text {II }}$

$281 \geq 1$, the cohesion and friction angle are constant at $C_{w}$ and $\varphi_{w}$. For the basement layer, $C_{i}$

282 and $C_{w}$ are $10^{7} \mathrm{~Pa}$ and $10^{6} \mathrm{~Pa}$, respectively, and $\varphi_{i}$ and $\varphi_{w}$ are $44^{\circ}$ (initial friction

283 coefficient $\mu_{i}=\sim 0.7$ ) and $30^{\circ}$ (weakened friction coefficient $\mu_{w}=\sim 0.5$ ), respectively.

284 The value of the weakened friction coefficient corresponds to the experimentally

285 determined values for phyllosilicate minerals, i.e., mica and chlorite (Morrow et al.

286 2000; Ikari et al. 2011), and the value for damage zones of the San Andreas fault 
287 (Carpenter et al. 2015). For the sediment layer, according to Gerya et al. (2009) and

288 Gerya (2010), the physical properties of $C_{i}=C_{w}=10^{6} \mathrm{~Pa}, \varphi_{i}=14^{\circ}$, and $\varphi_{w}=6^{\circ}$ are

289 employed for the calculation. The shear modulus $G$ of the upper basement layer and the

290 sediment layer is $1.0 \times 10^{10} \mathrm{~Pa}$, and that of the lower basement layer is $2.5 \times 10^{10} \mathrm{~Pa}$.

291 An energy conservation law that does not consider internal heat generation can be

292 expressed as

293

$294 \rho C_{p} \frac{\mathrm{D} T}{\mathrm{D} t}=\frac{\partial q_{x}}{\partial x}+\frac{\partial q_{z}}{\partial z}$

295

$$
q_{x}=k \frac{\partial T}{\partial x}, q_{z}=k \frac{\partial T}{\partial z}
$$

297 where $q_{x}$ and $q_{z}$ are the conductive heat fluxes in the horizontal and vertical directions,

298 respectively, $t$ is time [s], $\rho$ is the local density depending on the composition, $C_{p}$ is the specific heat at constant pressure, and $k$ is the thermal conductivity. According to Gerya

300 et al. (2009) and Gerya (2010), the values of $C_{p}$ for the sedimentary layer and the

301 basement are set to $1,000 \mathrm{~J} /(\mathrm{kg} \cdot \mathrm{K})$ and the value of $k[\mathrm{~W} /(\mathrm{m} \cdot \mathrm{K})]$ for the sedimentary

302 layer and the upper basement is $0.64+807 /(T+77)$ while that for the lower basement is 
304 Conservation of mass is approximated by the incompressible time-dependent

305 two-dimensional continuity equation:

306

$307 \quad \frac{\partial v_{x}}{\partial x}+\frac{\partial v_{z}}{\partial z}=0$

308

309 where $v_{x}$ and $v_{z}$ are the horizontal and vertical components of the velocity vector,

310 respectively.

311 The two-dimensional Stokes equations for creeping flow are

312

$313 \quad \frac{\partial \sigma_{x x}}{\partial x}+\frac{\partial \sigma_{x z}}{\partial z}=\frac{\partial P}{\partial x}$,

$314 \quad \frac{\partial \sigma_{z x}}{\partial x}+\frac{\partial \sigma_{z z}}{\partial z}=\frac{\partial P}{\partial z}-\rho g$,

316 where $g$ is the gravitational acceleration $\left(9.81 \mathrm{~m} / \mathrm{s}^{2}\right)$. In this study, the densities of the

317 sediment, upper basement, and lower basement are $2,600 \mathrm{~kg} / \mathrm{m}^{3}, 2,700 \mathrm{~kg} / \mathrm{m}^{3}$, and 2,800

$318 \mathrm{~kg} / \mathrm{m}^{3}$, respectively. A weak layer above the lithosphere ("sticky air", $\eta=10^{18} \mathrm{~Pa} \mathrm{~s}, \rho=$ 
$\left.3191 \mathrm{~kg} / \mathrm{m}^{3}, k=300 \mathrm{~W} /(\mathrm{m} \cdot \mathrm{K}), C_{p}=3.0 \times 10^{6} \mathrm{~J} /(\mathrm{kg} \cdot \mathrm{K})\right)$ provides a free-surface-like

320 condition, which is essential to transform crust or sediment naturally (Gerya and Yuen

3212003,2007 ; Gerya 2010).

322 The calculation domain in the initial state was $80 \mathrm{~km} \times 35 \mathrm{~km}$ (Fig. 4). The size of

323 the basement layers was $80 \mathrm{~km} \times 30 \mathrm{~km}$. All models used a finite-difference with

324 marker-in-cell technique and were conducted on a fully staggered rectangular Eulerian

325 grid with 4,480,000 markers. The grid spacing was irregular and was initially applied as

326 an $800 \times 210$ grid of $80 \mathrm{~km} \times 21 \mathrm{~km}$ in the upper domain and as an $800 \times 60$ grid of 80

$327 \mathrm{~km} \times 14 \mathrm{~km}$ in the lower domain. The grid spacing was recalculated at each time step to

328 accommodate the horizontal shortening described below. The initial position of each

329 marker was evenly set and then given random noise using the MATLAB ${ }^{\circledR}$ random

330 number generator and, in some cases, we changed the random seed to evaluate the

331 effect of the initial position of the markers. The absolute time step was $10 \mathrm{kyr}$. The

332 calculation time was set to $3 \mathrm{Myr}$ according to the fission track age (2.71 million years

333 ago; Itihara et al. 1984) of the volcanic ash layer at the bottom of the Osaka Group.

334 We applied free-slip conditions at all boundaries and constant leftward and 
downward velocities at the right and bottom boundaries, respectively. Temperatures at

336 the top and bottom boundaries were constant, i.e., $0{ }^{\circ} \mathrm{C}$ and $750{ }^{\circ} \mathrm{C}$, respectively, and

337 the right and left boundaries were adiabatic. An initial geothermal gradient of $25^{\circ} \mathrm{C} / \mathrm{km}$

338 (e.g., Okubo et al. 2005) was applied to the basement layer, whereas there was no

339 temperature gradient in the sticky air layer (i.e., the temperature at the top of the

340 basement layer was also $\left.0{ }^{\circ} \mathrm{C}\right)$. Following the horizontal shortening strain rate $(16-26 \times$

$34110^{-9} / \mathrm{yr}$ ) for central Japan of Wesnousky et al. (1982), the horizontal shortening rate was

342 set to $2 \mathrm{~m} / \mathrm{kyr}$ (Fig. 4). Therefore, at the end of the calculation (3 Myr), the $80-\mathrm{km}$-wide

343 crust was shortened by $6 \mathrm{~km}$. To conserve mass in the calculation domain, a changing

344 downward velocity (from $0.88 \mathrm{~m} / \mathrm{kyr}$ at $0 \mathrm{Myr}$ to $1.02 \mathrm{~m} / \mathrm{kyr}$ at $3 \mathrm{Myr}$ ) was applied at

345 the bottom boundary.

346 To model preexisting faults, strained zones with a strain, $\varepsilon_{\text {II }}$, of 1 , having the initial

$347 C_{w}$ and $\varphi_{w}$, and a yield stress or plastic strength weaker than the surrounding rock mass

348 were applied in the basement layer as high-strained weak zones. In this study, we refer

349 to such high-strained weak zones as "faults" or "fault zones". Even though the width of

350 a preexisting fault zone was set to $250 \mathrm{~m}$, that is, 2.5 times wider than the grid space, 
351 the width of the zone follows the scaling law of the linear relationship between the

352 width of the fault process zone and the fault length with a proportionality constant on

353 the order of $10^{-2}$ (Vermilye and Scholz 1998).

354 To model sedimentation processes, we introduced an imposed sea level change that

355 is consistent with the geologically observed sedimentation rate at the location of the

356 OD-1 core site. At the initial state, the sea level was set to the boundary between the

357 sticky air and the rock layer. At each time step, after all markers were moved according

358 to the calculated velocity field, we changed the sea level and markers of the sticky air

359 below the sea level were replaced with markers of the sedimentary layer. Surface

360 erosion was not considered in this study.

361 We considered three types of cases with the simulation model: (1) cases without any

362 preexisting fault zone; (2) cases with a single fault zone cutting the upper $12 \mathrm{~km}$ of the

363 basement layer; and (3) cases with two preexisting fault zones corresponding to the

364 Uemachi and Ikoma fault zones. 
368 In these cases, we did not consider sedimentation processes. In the cases without any

369 preexisting fault, under the compressive stress field, the upper and lower basement

370 layers deform homogeneously prior to 0.4-0.6 Myr, whereas after 0.4-0.6 Myr, in the

371 upper basement layer, the strain is concentrated into narrow zones and localized

372 high-strained zones, i.e., newly formed thrust faults that develop as a result of

373 compression (Fig. 5). These cases demonstrate that simulation results with different

374 random seeds at 3 Myr differ somewhat with respect to the dip directions of the newly

375 formed thrust faults. The thrust faults grow downward from the surface because values

376 of the yield stress $\sigma_{\text {yield }}$ of a rock given by Eq. (3) are lower at shallower depths. They

377 develop from the surface to the frictional-viscous transition zone, where the strain is

378 accommodated primarily by frictional deformation with weakened friction $\left(\mu_{w}\right)$ relative

379 to the viscous deformation (inset in Fig. 4). The dip angles of the faults are $\sim 30^{\circ}$ near

380 the surface but bend gently near the frictional-viscous transition depth. These fault

381 geometries (i.e., dip angles of the faults) are not explicitly "determined" by the code but

382 form spontaneously during the propagation of the high-strained zone involving markers 
383 for which the yielding condition given by Eq. (3) is satisfied locally. When increasing

384 the amount of horizontal shortening, the thickness of the early formed faults widens and

385 becomes $\sim 300-500 \mathrm{~m}$ at $3 \mathrm{Myr}$; however, the depth of the fault tips does not change

386 significantly after $\sim 2$ Myr. In the lower basement layer, the strain is distributed to form

387 large-scale folds instead of localized high-strained zones. The displacement along the

388 faults leads to relative subsidence on the lower side of the faults or uplifting on the

389 upper side. In general, the amount of vertical displacement decreases with distance from

390 the faults. The blocks between faults with the same dip direction tilt antithetically (Fig.

391 5a), whereas the blocks between faults with opposite dip directions rise or sink

392 vertically (Fig. 5b).

393

394 Cases with a single preexisting fault zone

395 In these cases, we did not consider sedimentation processes. In the cases with a single

396 fault zone, we set the fault to have different dip angles (i.e., $15^{\circ}, 30^{\circ}, 45^{\circ}$, and $60^{\circ}$ ) at

397 the surface location of $x=23 \mathrm{~km}$. Based on the simulation results for the cases with no preexisting fault, because the local displacements in the strained zone in the deepest part 
399 of the upper basement layer and the lower basement layer are negligible, we considered

400 the faults as only preexisting above $12 \mathrm{~km}$. In this case, the effect of changing the

401 random seed is smaller than in the cases without a preexisting fault and we only show

402 the results with the random seed $=1$ in Fig. 6 . In all the cases, at the initial stage, strain

403 localization occurs in the preexisting fault zone. The zone widens and becomes a source

404 for newly generated spray fault zones. Displacement occurs along the preexisting faults

405 in the upper basement layer for dip angles of $15^{\circ}-45^{\circ}$ but not $60^{\circ}$ (Fig. 6). When the dip

406 angle of the preexisting fault is $15^{\circ}$ or $45^{\circ}$, the displacement along the preexisting fault

407 is relatively small and new high-strained zones with dip angles of $\sim 30^{\circ}$ develop. The

408 preexisting fault steepens by $\sim 2^{\circ}$ because of the rotation of the fault during horizontal

409 shortening. When the dip angle of the preexisting fault is $30^{\circ}$, which is suitable for

410 horizontal compression, the displacement along the fault is significant and the fault

411 ultimately steepens by $\sim 10^{\circ}$ as a result of the horizontal shortening and the tilting of the

412 upper basement layer. After the preexisting fault becomes steeper, new faults with dip

413 angles of $\sim 30^{\circ}$ are formed. Conversely, when the dip angle of the preexisting fault is $60^{\circ}$,

414 many new faults with dip angles of $\sim 30^{\circ}$ are formed and evenly displaced; in this case, 
415 the preexisting fault ultimately steepens by $\sim 2^{\circ}$.

416 When the faults contain large amounts of clay minerals, the experimentally derived

417 friction coefficient for the fault zone decreases to $~ 0.1-0.2$ (Takahashi et al. 2007; Ikari

418 et al. 2011). In fact, the frictional strength estimated for the weakest section of the San

419 Andreas fault is $\sim 0.1$ but increases abruptly to a value of $\sim 0.4-0.5$ in the host

420 sedimentary rocks (Carpenter et al. 2015). We performed a simulation for a single

421 preexisting fault zone with lower friction values of $\mu_{w}=\sim 0.4$ and $\sim 0.3\left(\varphi_{w}=24^{\circ}\right.$ and

$42217^{\circ}$, respectively). Figure 7 shows the results of the effect of the different weakened

423 friction values on the activity of a preexisting fault with a dip angle of $60^{\circ}$. In this case,

424 the preexisting fault, which is not favorably oriented to the horizontal compressional

425 stress field, is active under the condition of $\mu_{w}<0.4$.

426

427 Cases with two preexisting fault zones

428 In these cases, we consider the sedimentation process. We set two faults, whose

429 locations at the surface were $x=23 \mathrm{~km}$ (i.e., the western fault) and $x=40 \mathrm{~km}$ (i.e., the

430 eastern fault). The western and eastern faults correspond to the Uemachi and Ikoma 
431 faults, respectively, which are separated by $\sim 14 \mathrm{~km}$ at the surface in the final state. At

432 the location equivalent to $x=18 \mathrm{~km}$ in the initial state, corresponding to the OD- 1 core

433 site, which is $\sim 5 \mathrm{~km}$ west of the Uemachi fault, we set the mean sedimentation rate to

434 deposit $900 \mathrm{~m}$ of the Miyakojima Formation and $650 \mathrm{~m}$ of the Tanaka and Namba

435 formations (i.e., $0.5 \mathrm{~m} / \mathrm{kyr}$ from 0 to $1.8 \mathrm{Myr}, 0.6 \mathrm{~m} / \mathrm{kyr}$ from $1.8 \mathrm{Myr}$ to $2.6 \mathrm{Myr}$, and

$4360.4 \mathrm{~m} / \mathrm{kyr}$ from 2.6 Myr to 3.0 Myr). Because Quaternary sediments are basically absent

437 in the Ikoma Mountains (with a highest elevation of $642 \mathrm{~m}$ ), the Ikoma Mountains may

438 have been separated from the marine waters at 3 million years ago (Ma). However,

439 because the elevation of the Ikoma Mountains at $3 \mathrm{Ma}$ is unknown, the elevation of the

440 Ikoma Mountains was assumed to be $0 \mathrm{~m}$ at $3 \mathrm{Ma}$ (at $0 \mathrm{Myr}$ in this study). According to

441 the results for the cases with a single fault zone (Fig. 6), the optimal dip angle for the

442 resolved shear stress is $\sim 30^{\circ}$ and the dip angles of the western and eastern faults should

443 also be $\sim 30^{\circ}$. Based on the geological interpretation, because the vertical displacement

444 rate related to the Ikoma fault has been estimated to be much higher than that related to

445 the Uemachi fault (Table 1), the dip angle of the western fault was set to differ slightly

446 from the optimal value for the resolved shear stress, or the friction coefficients for the 
447 eastern fault were set to be lower than those for the western fault. Because previous

448 studies have generally suggested that the dip angle of the Uemachi fault is steeper than

449 that of the Ikoma fault (Fig. 1) and because the dip angle of the Uemachi fault was

450 recently estimated to be $\sim 40^{\circ}$ (Kato and Ueda 2019), we applied dip angles of $40^{\circ}$ and

$45130^{\circ}$ to the western and eastern faults, respectively (Fig. 8a). In this case, the downward

452 extension of the western fault nearly coincides with the epicenter of the 2018 northern

453 Osaka earthquake.

454 We compared the simulation results and geologic structures proposed by Uchiyama

455 et al. (2001, Fig. 3) based on the following points: (1) the large-scale variation in the

456 thickness of the upper and uppermost sedimentary layers, corresponding to the Tanaka

457 and Namba formations, in the area in-between the western and eastern faults, i.e., in east

458 Osaka, especially at the location of the OD-9 core site $(\sim 2 \mathrm{~km}$ east from the Uemachi

459 fault at the final state) in the Uemachi Upland and at the location of the OD-3 core site

460 ( 9 km east from the Uemachi fault at the final state) near the Onchi River, and (2) the

461 vertical displacement rates after 1.8 Myr, corresponding to the sedimentation period of

462 the Tanaka and Namba formations, estimated by the vertical differences between the 
463 highest point of the hanging wall basement and the lowest point of the foot wall

464 basement near the western and eastern faults.

465 The displacement along the western and eastern faults leads to relative subsidence on

466 the lower side of the faults so that sediment layers form in the relative subsidence

467 regions (Fig. 8a). The surface of the basement slopes to the east as a whole, and an

468 eastward thickening of the sedimentary layers throughout the Osaka Plain is observed.

469 These layers result from the displacement along the eastern fault being much larger than

470 that along the western fault (Table 1). The region west of the eastern fault is tilted

471 eastward as a whole, even though displacement along the western fault and a difference

472 in the sedimentary layer thickness between the areas on both sides of the western fault

473 are observed. As shown in Fig. 8b, the vertical displacement rates related to the western and eastern faults increase monotonically prior to $\sim 0.5$ Myr. At the initial stage $(<\sim 0.5$

475 Myr) of the simulation, the deformation does not concentrate along the entire fault; the

476 deformation front moves downward along the fault, and then the entire fault deforms

477 after $\sim 0.5$ Myr. Therefore, the monotonical increase in the displacement rate at the

478 initial stage of the simulation results from the increase in the deforming length along the 
479 faults. The vertical displacement rate related to the eastern fault increases to $\sim 1 \mathrm{~m} / \mathrm{kyr}$ at

$480 \sim 1$ Myr and becomes stable, whereas that along the western fault increases to $\sim 0.3$

$481 \mathrm{~m} / \mathrm{kyr}$ at $\sim 0.5 \mathrm{Myr}$ and then decreases. This implies that the deformation of the eastern

482 fault is predominant after $\sim 0.5 \mathrm{Myr}$, even though the deformation is more partitioned in

483 the eastern fault, and then the western and eastern faults deform stably after $\sim 1$ Myr.

484 The mean vertical displacement rates along the western and eastern faults for the last 1

485 Myr are $\sim 0.07 \mathrm{~m} / \mathrm{kyr}$ and $\sim 0.8 \mathrm{~m} / \mathrm{kyr}$, respectively (Fig. $8 \mathrm{~b}$ and Table 1 ). The mean

486 displacement rate along the western fault is much slower than the inferred displacement

487 rate along the Uemachi fault ( 0.3-0.4 mm/yr; Uchiyama et al. 2001; Headquarters for

488 Earthquake Research Promotion of MEXT 2001), whereas that along the eastern fault

489 corresponds to the inferred displacement rate along the Ikoma fault $(0.5-1 \mathrm{~m} / \mathrm{kyr}$;

490 Shimokawa et al. 1997).

491 The depth of the basement surface is approximately $1,400 \mathrm{~m}$ at the location of the

492 OD-9 core site in the Uemachi Upland and approximately 1,900 $\mathrm{m}$ at the location of the

493 OD-3 core site near the Onchi River (Table 1). Both results are deeper than the

494 geologically inferred values. The thickness of the sediment layer, corresponding to the 
495 Tanaka and Namba formations, increases eastward; it is 690-m thick near the Uemachi

496 Upland and $~ 870-\mathrm{m}$ thick near the Onchi River. Both results are thicker than the

497 geologically inferred value. The sedimentation rate near the Onchi River is $0.7 \mathrm{~m} / \mathrm{kyr}$

498 for the period of 1.8-2.4 Myr, corresponding to the lower Tanaka Formation, whereas

499 that near the Uemachi Upland is $0.6 \mathrm{~m} / \mathrm{kyr}$ for the same period (Fig. 8c); the former is

500 consistent with geologically inferred values, but the latter is faster than the geologically

501 inferred values (Table 1). However, although the sedimentation rate near the Onchi

502 River hardly changes from 1.8 Myr to 2.4 Myr, the geologically inferred sedimentation

503 rate decreases from 1.2 Ma to 0.6 Ma (Uchiyama et al. 2001). Consequently, in this case,

504 the thicknesses of the upper and uppermost sedimentary layers corresponding to the

505 lower Tanaka Formation and the upper Tanaka and Namba formations near the Uemachi

506 Upland differ from the geological interpretation by $\sim 160 \mathrm{~m}$ and $\sim 280 \mathrm{~m}$, respectively.

507 The mean displacement rate along the western fault is smaller than that inferred from

508 the geological observations. To resolve this discrepancy, the displacement rate along the

509 western fault needs to be enhanced by decreasing the dip angle of the fault at least

510 partially and/or by decreasing the friction coefficients. Accordingly, we evaluated 
511 gentler $\left(30^{\circ}\right)$ or curved western fault cases (Fig. 9). In the curved fault cases, the dip

512 angle of the western fault is $40^{\circ}$ at the surface and gradually decreases with depth. The

513 dip angle of the deeper part $(>7 \mathrm{~km})$ of the western fault is constant and is $20^{\circ}$ in the

514 curved fault case and $15^{\circ}$ in the more curved fault case.

$515 \quad$ Figure 9a illustrates the results of the case with the gentler dip angle $\left(30^{\circ}\right)$ for the

516 western fault (the gentler Uemachi case). The displacement rate along the western fault

517 is much higher than that in the case with the dip angle of the western fault set to $40^{\circ}$,

518 whereas the displacement rate along the eastern fault is lower, implying that more

519 deformation is partitioned to the western fault, decreasing the displacement rate along

520 the eastern fault. Although the dip angle of the both faults is the same, the displacement

521 rate along the western fault is lower than that along the eastern fault. It may be resulted

522 from the effects of viscous flow near the bottom of the lower basement layer; when the

523 adjacent, parallel preexisting faults are eastward dipping, the downward extension of the easternmost fault (i.e., the eastern fault in this case) develops as a lower crustal

525 high-strained zone connecting to the basal viscous flow and then the strain localizes into

526 the eastern fault (Additional file 1: Fig. S1). The eastern fault and its downward 
extension act as a bounding fault between the less deformed hanging wall and footwall

528 blocks. A local uplift of the high-strained triangular zone of the sedimentary layers in

529 between conjugate fault set propagated from the tip of the western fault is observed. The

530 formation of the conjugate fault set may be resulted from the increase in the

531 displacement rate and/or the decrease in the dip angle of the western fault. Based on a

532 comparison with the geological interpretation, this gentler Uemachi case is more

533 suitable; however, the difference between the geological interpretation and the

534 simulation results is still large, especially the thickness of the uppermost sedimentary

535 layer in the Uemachi Upland and the basement depth near the Onchi River (Table 1).

536 The results of the curved fault cases (the curved and more curved Uemachi cases) are

537 illustrated in Fig. 9b-e. Nearly horizontal sedimentary layers form in west Osaka,

538 whereas an eastward thickening of the sedimentary layers is observed in east Osaka.

539 The surface of the basement in east Osaka slopes to the east, whereas that in west Osaka

540 is nearly horizontal. These slopes result from the clockwise rotation of the east Osaka

541 block arising from the displacement along the synthetic eastern and western faults. The

542 degree of tilting toward the east of the east Osaka block in the curved western fault 
543 cases is larger than that in the non-curved cases; however, the difference in the degree of

544 tilting between the curved and more curved cases is not significant. The thickness of the

545 sediment layer in east Osaka in the more curved western fault case is larger than that in

546 the less curved case (Table 1). Based on a comparison with the geological interpretation,

547 the less curved case is the more suitable geometry for the present numerical model. In

548 the curved fault case, the numerical results are consistent with the geological

549 interpretation, even though the thickness of the uppermost sedimentary layer near the

550 Uemachi Upland differs from the geological interpretation by $\sim 170 \mathrm{~m}$. This difference

551 may be reduced by a higher vertical displacement rate along a fine-tuned, optimally

552 curved western fault.

553 The difference in the thickness of the uppermost sedimentary layer between the

554 simulation results and the geological interpretation may also be due to the effect of the

555 changing sedimentation rate for the uppermost sedimentary layer. In this study, we set

556 the mean sedimentation rate at the OD-1 core site to $0.4 \mathrm{~m} / \mathrm{kyr}$ from $2.6 \mathrm{Myr}$ to $3.0 \mathrm{Myr}$,

557 even though the sedimentation rate from $\sim 0.4$ Ma to $\sim 0.05$ Ma actually decreased from

$5580.5 \mathrm{~m} / \mathrm{kyr}$ to $0.2 \mathrm{~m} / \mathrm{kyr}$ (Uchiyama et al. 2001). Furthermore, in the present simulation 
559 models, the subsidence rate in west Osaka decreases with distance from the western

560 fault, even though, based on gravity and seismic reflection data (e.g., Nakagawa et al.

561 1996b; Iwabuchi 2000), the top of the basement deepens toward the west and the

562 deepest part of the Osaka Bay is located $\sim 27 \mathrm{~km}$ from the Uemachi fault, where the

563 NNE-SSW-trending Osaka-wan fault is located. The Osaka-wan fault is an

564 ESE-side-down reverse fault, having a mean vertical displacement rate of $0.5-0.6 \mathrm{~m} / \mathrm{kyr}$

565 after $1 \mathrm{Ma}$ (Yokokura et al. 1998). If the subsidence rate at the OD-1 site related to the

566 activity of the Osaka-wan fault is higher than that used in the present models, the

567 sedimentation rate in east Osaka will be lower because the rising rate of the sea level

568 will be reduced. Further studies need to evaluate the effect of changing the

569 sedimentation rate and vertical displacement along the Osaka-wan fault on the

570 development of the geologic structures of the upper and uppermost sedimentary layers.

572 Evaluation of previously proposed fault geometry models

573 As previously mentioned, geometries of the deeper parts of the Uemachi and Ikoma

574 faults have been proposed by Ishiyama (2003) and Sato et al. (2009). In this section, we 
evaluate their proposed Uemachi and Ikoma fault geometries.

576 Following Ishiyama (2003), we applied two faults initially in the basement layer with

577 the western and eastern faults corresponding to the Uemachi and Ikoma faults,

578 respectively (Fig. 10a). The dip angles of the western and eastern faults near the surface

579 were $40^{\circ}$ and $55^{\circ}$, respectively. The surface positions of the two faults were the same as

580 in the cases with two preexisting fault zones. The eastern fault was linear, whereas the

581 western fault had a downward convex curving part at a depth of $\geq 1.5 \mathrm{~km}$, became nearly

582 horizontal $\left(2^{\circ}\right)$ at a depth of $3.5 \mathrm{~km}$, and then converged to the eastern fault at a depth of

$583 \sim 4 \mathrm{~km}$. Because a preexisting weak fault with a dip angle of $\sim 60^{\circ}$ is active when the

584 weakened friction coefficient $\left(\mu_{w}\right)$ is less than $\sim 0.3$, we performed numerical

585 simulations for this case with $\mu_{w}=0.3$. In this case, even though the eastern fault (dip

586 angle of $55^{\circ}$ ) was active, displacement related to the western fault (dip angle of $40^{\circ}$ ) is

587 not significant and does not occur along the deeper $(>3.5 \mathrm{~km})$ and horizontal $\left(<2^{\circ}\right)$ parts

588 of the fault. A newly formed fault with a dip angle of $\sim 30^{\circ}$ propagates from the

589 shallower and steeper parts of the western fault, and displacement related to the

590 Uemachi fault occurs along this newly formed fault. This result implies that a 
thin-skinned thrust converging to a low-angle detachment in the upper crust would not

592 be active. The displacement along the eastern fault is significant but a large-scale

593 downward fold, i.e., synform, is formed in the area east to the eastern fault, leading to

594 the development of a sedimentary basin.

595 According to Sato et al. (2009), the western fault has a near surface dip angle of $50^{\circ}$,

596 transitions to gently dipping at a depth of $\leq 7 \mathrm{~km}$, and then converges to the eastern fault

597 at a depth of $\sim 9 \mathrm{~km}$ (Fig. 10b) with a dip angle of $4^{\circ}$. The dip angle of the eastern fault

598 near the surface was set to $45^{\circ}$, and the eastern fault transitioned to gently dipping at a

599 depth of $5 \mathrm{~km}$. Below the converged depth, the dip angle of the eastern fault was set to

$60020^{\circ}$. The surface positions of the two faults were the same as in the cases with two

601 preexisting fault zones. We performed numerical simulations for this case with $\mu_{w}=0.4$.

602 The simulation results are similar to the curved Uemachi case (Figs. 9b and 10b), which

603 correspond roughly to the geological interpretation (Table 1). The displacements along

604 the lower $(>9 \mathrm{~km})$ and horizontal $\left(<4^{\circ}\right)$ parts of the Uemachi fault are not significant,

605 and the newly formed high-strained zones with a dip angle of $\sim 30^{\circ}$ propagate from the

606 upper bound of the lower and horizontal parts (Additional file 1: Fig. S2). Therefore, the 
607 actual fault geometry of this model is similar to our curved Uemachi case at shallower

608 depths $(<\sim 10 \mathrm{~km})$.

609

610 Concluding remarks

611 Based on a simple numerical analysis, we can conclude that, when the friction

612 coefficient of the faults is approximately 0.5 , the dip angles of the Uemachi and Ikoma

613 faults near the surface are $\sim 30^{\circ}-40^{\circ}$ and the Uemachi fault has a downward convex

614 curve at the bottom of the seismogenic zone but does not converge to the Ikoma fault.

615 This implies that the downward extension of the Uemachi fault zone nearly coincides

616 with the epicenter of the 2018 northern Osaka earthquake.

617

618 Abbreviations

619 MEXT: Ministry of Education, Culture, Sports, Science and Technology of Japan.

620

621 Author's contributions

$622 \mathrm{HN}$, TO and KI performed the numerical simulations and evaluated the model results. 
$623 \mathrm{MM}$ evaluated the geological features in the Osaka Plain to constrain the model

624 results. HN and TO drafted mainly the manuscript, and all authors read and approved

625 the final manuscript.

626

627 Acknowledgements

628 We thank TV Gerya for his providing the I2ELVIS code via the Cambridge University

629 Press website (https://www.cambridge.org/9780521887540).

630

\section{Competing interests}

632 The authors declare that they have no competing interests.

633

634 Availability of data and materials

635 All data generated or analyzed during this study are available from the corresponding

636 author on reasonable request.

637

638 Consent for publication

Nishiwaki et al. 40 
639 Not applicable.

640

$641 \quad$ Funding

642 This study supported by JSPS KAKENHI Grant Number 20 Ko4087.

643

644 References

645 Allken V, Huismans RS, Thieulot C (2012) Factors controlling the mode of rift

646 interaction in brittle-ductile coupled systems: A 3D numerical study. Geochem

647 Geophys Geosystem 13, Q05010. https//doi.org/10.1029/2012GC004077

648 Allmendinger RW (1998) Inverse and forward numerical modeling of trishear

649 fault-propagation folds. Tectonics 17:640-656

650 Carpenter BM, Saffer DM, Marone C (2015) Frictional properties of the active San

651 Andreas Fault at SAFOD: Implications for fault strength and slip behavior. J

652 Geophys Res 120:5273-5289. https://doi.org/10.1002/2015JB011963

653 Director General for Disaster Management (2006) Evaluation of inundation possibility

654 associated with crustal deformation due to earthquake in the Uemachi fault zone. 
656 kohyo.pdf. Accessed 10 Sept 2020

657 Döhmann MJEA, Brune S, Nardini L, Rybacki E, Dresen G (2019) Strain localization and 658 weakening processes in viscously deforming rocks: Numerical modeling based on 659 laboratory torsion experiments. J Geophys Res: Solid Earth 124:1120-1137. 660 https://doi.org/10.1029/2018JB016917

661 Gerya T (2010) Introduction to Numerical Dynamic Modelling. Cambridge Univ Press, $662 \quad$ New York

663 Gerya TV, Yuen DA (2003) Rayleigh-Taylor instabilities from hydration and melting 664 propel 'cold plumes' at subduction zones. Earth Planet Sci Lett 212:47-62. 665 https://doi.org/10.1016/So012-821X(03)00265-6

666 Gerya TV, Yuen DA (2007) Robust characteristics method for modelling multiphase 667 visco-elasto-plastic thermo-mechanical problems. Phys Earth Planet Int 163:83-105. 668 https://doi.org/10.1016/j.pepi.2007.04.015

669 Gerya TV, Fossati D, Cantieni C, Seward D (2009) Dynamic effects of aseismic ridge 670 subduction: numerical modelling. Eur J Mineral 21:649-661. 
671 https://doi.org/10.1127/0935-1221/2009/0021-1931

672 Headquarters for Earthquake Research Promotion of MEXT (2001) Long-term

673 evaluation of lkoma fault zone.

674 http://www.jishin.go.jp/main/chousa/katsudansou_pdf/77_ikoma.pdf. Accessed 10

675 Sept 2020

676 Headquarters for Earthquake Research Promotion of MEXT (2004) Long-term

677 evaluation of Uemachi fault zone.

678 http://www.jishin.go.jp/main/chousa/katsudansou_pdf/8o_vemachi.pdf. Accessed

$679 \quad 10$ Sept 2020

680 Horike M, Takeuchi Y, Toriumi I, Fujita T, Yokota H, Noda T (1995) Seismic reflection

681 survey of the boundary region between the Ikoma mountains and the Osaka basin.

682 Zisin 48:37-49

683 Huzita K (1968) Rokko movements and its appearance -Intersecting structural

684 patterns of southwest Japan and Quaternary crustal movements-. Quaternary Res

685 (Daiyonki-Kenkyu) 7:248-260

686 Huzita K (1990) Manchidani Unconformity and Rokko movements -Middle 
687 Pleistocene fault-block movement and sea-level rise in Kinki, Japan Quaternary Res

688 (Daiyonki-Kenkyu) 29:337-349

689 Huzita K, Kasama T (1982) Geology of the Osaka-Seinambu district, Quadrangle Series,

690 scale 1:50,000, Geological Survey of Japan, Tsukuba

691 Ikari MJ, Marone C, Saffer DM (2011) On the relation between fault strength and

692 frictional stability. Geology 39:83-86. https://doi.org/10.1130/G31416.1

693 Ikebe N, Huzita K (1966) The Rokko movements, the Pliocene-Pleistocene crustal

694 movements in Japan. Quaternaria 8:277-287

695 Ikebe N, Iwatsu J, Takenaka J (1970) Quaternary geology of Osaka with special

696 reference to land subsidence. J Geosci Osaka City Univ 13:39-98

697 Ishiyama T (2003) Geometry and kinematics of the Uemachi and Ikoma fault zones

698 beneath Metropolitan Osaka, central Japan. Ann Rep Active Fault Paleoearthquake

$699 \quad$ Res, no.3, p.145-155

700 Itihara M (1993) Osaka Group. Sogensha Publishing, Osaka

701 Itihara M, Yoshikawa S, Kawabe T, Mitamura M (1984) On so-called "Shiba

702 Unconformity" in the drainage area of the River Tsuda, Kishiwada City, Osaka - 
703 Magnetostratigraphy and fission track age of the Osaka Group-. Earth Sci

$704 \quad$ (Chikyu-Kagaku) 38:1-16

705 Itoh Y, Takemura K, Ishiyama T, Tanaka Y, Iwaki H (2000) Basin formation at a

706 contractional bend of a large transcurrent fault: Plio-Pleistocene subsidence of the

$707 \quad$ Kobe and northern Osaka Basin, Japan. Tectonophysics 321:327-341

708 Iwabuchi Y (2000) Active structures in Osaka Bay and Ise Bay. Quaternary Res

709 (Daiyonki-Kenkyu) 39:303-314

710 Iwasaki Y (2016) Fundamental mistake for estimation of the strong ground motion

711 and displacements from Uemachi fault earthquake by the Central Disaster

712 Management Council of the Cabinet Office, Government of Japan. Geoinformatics

$713 \quad 27: 66-69$

714 Kansai Geo-informatics Council (1998) New Kansai-jiban, Kobe and Hanshin Regions.

$715 \quad$ Kansai Geoinformatics Agency/Geo-Research Institute, Osaka

716 Kato A, Ueda T (2019) Source fault model of the $2018 M_{\mathrm{W}} 5.6$ northern Osaka

717 earthquake, Japan, inferred from the aftershock sequence. Earth Planets Space

718 71:11. https://doi.org/10.1186/s40623-019-0995-9 
720 and subsurface structure of Holocene deposits around Uemachi Upland in the

721 central Osaka Plain. J Geosci Osaka City Univ 37:183-212

722 Morrow CA, Moore DE, Lockner DA (2000) The effect of mineral bond strength and

723 adsorbed water on fault gouge frictional strength. Geophys Res Lett 27:815-818

724 Nakagawa K, Inoue N, Ryoki K (1996a) Basement structure of Osaka basin. Urban

725 Earthquake Hazard Res Center Rep, no. 18, p.11-25

726 Nakagawa K, Shiono K, Inove N, Sano M (1996b) Geological characteristics and

727 problems in and around Osaka Basin as a basis for assessment of seismic hazard.

728

Soils

and

Foundations

36

(Supplement):15-28.

729

https://doi.org/10.3208/sandf.36.Special_15

730 Nakata T, Okada A, Suzuki Y, Watanabe M, Ikeda Y (1996a) 1:25,000-scale Active Fault

731 Map in Urban Area, Osaka Tohoku-bu. Technical Materials of the Geographical

732 Survey Institute, D.1-no. 333

733 Nakata T, Okada A, Suzuki Y, Watanabe M, Ikeda Y (1996b) 1:25,000-scale Active Fault

734 Map in Urban Area, Osaka Tonan-bu. Technical Materials of the Geographical 
736 Okada A, Togo M (2000) Active Faults in the Kinki Area, Central Japan: Sheet Maps and 737 Inventories. Univ Tokyo Press, Tokyo

738 Okada A, Yagi, H (2019) Illustrated Active faults in Japan. Asakurashoten Publishing, $739 \quad$ Tokyo

740 Okada A, Uemura Y, Togo M, Nakata T, Watanabe M (1996) 1:25,000-scale Active Fault 741 Map in Urban Area, Kyoto Seinan-bu. Technical Materials of the Geographical 742 Survey Institute, D.1-no. 333

743 Okubo Y, Uchida Y, Taniguchi M, Miyakoshi A, Safanda J (2005) Statistical analysis for 744 thermal data in the Japanese Islands. Phys Earth Planet Inter 152:277-291. 745 http://doi.org/10.1016/j.pepi.2005.04.013

746 Osaka Prefecture (2004) Survey for the underground structure in the Osaka Plain.

747 Report for basic earthquake-related survey grant FY2003, Osaka

748 Ruh JB, Gerya T, Burg JP (2014) 3D effects of strain vs. velocity weakening on

749 deformation patterns in accretionary wedges. Tectonophysics 615-616:121-141.

750 http://dx.doi.org/10.1016/jtecto.2014.01.003 
751 Sato H, Ito K, Abe S, Kato N, Iwasaki T, Hirata N, Ikawa T, Kawanaka T (2009) Deep

752 seismic reflection profiling across active reverse faults in the Kinki Triangle, central

753 Japan. Tectonophysics 472:86-94. https://doi.org/10.1016/j.tecto.2008.06.014

754 Shimokawa K, Kariya Y, Miyachi Y, Sangawa A (1997) Survey for the activity of the

755 Ikoma fault system. GSJ Open-file Rep, no. 303, p.37-49

756 Sugiyama $Y$ (1997) Seismic reflection survey of the Uemachi fault system. GSJ

757 Open-file Rep, no. 303, p.105-113

758 Sugiyama Y, Sangawa A (1996) Seismic reflection survey of the southward extension

759 of the Uemachi fault in the Yamato River, southern Osaka Plain. GSJ Interim Rep, no.

$760 \quad E Q / 96 / 1$, p. $57-62$

761 Sugiyama Y, Shimokawa K, Awata Y, Satake K, Mizuno K, Yoshioka T, Komatsubara T,

762

Nanayama F, Kariya Y, Azuma T, Fusejima Y, Tsukuda E, Sangawa A, Sugai T (1999)

763

Summarized survey result and earthquake potential of major active faults in the

764

Kinki Triangle, central Japan. GSJ Interim Rep, no. EQ/99/3, p.285-309

765

Sugiyama Y, Nanayama F, Kitada N, Yokota H (2001) S-wave seismic reflection survey

766 of the Uemachi fault in Osaka City. Ann Rep Active Fault Paleoearthquake Res, no. 

1, p.143-151

Sugiyama Y, Nanayama F, Miura K, Yoshikawa T, Yokota H, Suehiro M, Furutani M,

769 Tochimoto Y, Hirose K, Yokoyama Y, Kitada N, Takemura K (2003) Complementary

770 study of the Uemachi fault system in the Osaka Basin (2) -Evaluation of the fault activity based on supplementary boring and re-interpretation of S-wave seismic reflection data-. Ann Rep Active Fault Paleoearthquake Res, no. 3, p.117-144

Suzuki K (2016) Sedimentation rate and sedimentary process of the lower half of the Lower part of the Osaka Group, central Japan. J Sediment Soc Japan 75:25-34 the frictional strength and fluid transport property of faults. J Geophys Res 112:Bo8206. https://doi.org/10.1029/2006JB004678 inverted from centroid moment tensor data of seismic events. Tectonics 29:TC6oo8. https://doi.org/10.1029/2009TC002626

781 Tsukahara H, Kobayashi Y (1991) Crustal stress in the central and western parts of 
783 Tsutsumi H, Sato K, Yamaji A (2012) Stability of the regional stress field in central

784 Japan during the late Quaternary inferred from the stress inversion of the active

785 fault data. Geophys Res Lett 39:L23303. https://doi.org/10.1029/2012GL054094

786 Uchiyama M, Mitamura M, Yoshikawa S (2001) Displacement rate of the Uemachi

787 Fault and basement block movements of the Osaka Plain, Southwest Japan. J Geol

788 Soc Japan 107:228-236

789 Vermilye JM, Scholz CH (1998) The process zone: A microstructural view of fault

$790 \quad$ growth. J Geophys Res 103:12223-12237

791 Wesnousky SG, Scholz CH, Shimazaki K (1982) Deformation of an island arc: Rates of

792 moment release and crustal shortening in intraplate Japan determined from

793 seismicity and Quaternary fault data. J Geophys Res 87:6829-6852

794 Yokokura T, Kano N, Yamaguchi K, Miyazaki T, Ikawa T, Ohta Y, Kawanaka T, Abe S

795 (1998) Seismic profiling of deep geological structure in the Osaka Bay area. Bull

796 Geol Surv Japan 49:571-590

797 Yoshikawa S, Mitamura M (1999) Quaternary stratigraphy of the Osaka Plain, central

798 Japan and its correlation with oxygen isotope record from deep sea cores. J Geol 
799 Soc Japan 105:332-340

800 Yoshikawa S, Machida Y, Teramoto M, Yokota H, Nagao H, Kagiwara M (1987)

801 Reflection seismic survey in Osaka City. Proc 77th SEGJ Conf, p.114-117

802 Yoshikawa S, Mizuno K, Katoh S, Satoguchi Y, Miyakawa C, Kinugasa Y, Mitamura M,

803 Nakagawa K (2000) Stratigraphy and correlation of the Plio-Pleistocene volcanic

804 ash layers from a 1,700 m core taken from Higashinada, Kobe City, southwestern

805 Japan. Quaternary Res (Daiyonki-Kenkyu) 39:505-520

806

Nishiwaki et al. 51 


\section{Figure legends}

808 Fig. 1 Summary of the inferred geometries of the Uemachi and Ikoma faults in the

809 Osaka Plain illustrated on a schematic geological cross section (modified partially

810 from Ishiyama 2003). Here, references 1, 2, 3, 4, 5 and 6 correspond to Headquarters

811 for Earthquake Research Promotion of MEXT (2001, 2004), Ishiyama (2003), Director

812 General for Disaster Management (2006), Sato et al. (2009), Iwasaki (2016) and Kato

813 and Ueda (2016), respectively. The epicenter of the 2018 northern Osaka earthquake

814 (EQ) proposed by Kato and Ueda (2019), located $12 \mathrm{~km}$ beneath the surface position

$81514 \mathrm{~km}$ from the Uemachi fault, is indicated by a star.

816 Fig. 2 a Locations of the drilling sites on the Osaka Plain referred to in this study.

817 Faults and flexures of the Uemachi fault zone include the Uemachi fault (Um1),

818 Sakuragawa flexure (Um2), Nagai fault (Um3), and Suminoe flexure (Um4), and those

819 of the Ikoma fault zone include the Katano fault (Ik1), Hirakata fault (Ik2), and Ikoma

820 fault (lk3) (Headquarters for Earthquake Research Promotion of MEXT 2001, 2004).

821 The inset indicates the location of the study area. $\mathbf{b}$ Columnar sections of the OD-1, TS,

822 YU, OD-9, OT, OD-2, HA, and OD-3 drilling cores (partially modified from Uchiyama et 
824 Fig. 3 Schematic E-W geological section through the Osaka Plain (Uchiyama et al. 825 2001).

826 Fig. 4 Model geometry and boundary conditions. The inset shows the crustal strength

827 profile at the initial state in the numerical model. $\dot{\varepsilon}, \mu_{i r}$ and $\mu_{w}$ are the strain rate, the 828 initial friction coefficient, and the weakened friction coefficient, respectively. A 829 changing downward velocity (from $0.88 \mathrm{~m} / \mathrm{kyr}$ at o Myr to $1.02 \mathrm{~m} / \mathrm{kyr}$ at $3 \mathrm{Myr}$ ) is 830 applied at the bottom boundary.

831 Fig. 5 Results at 3 Myr for the numerical simulations with no preexisting fault zone.

832 The newly formed faults (markers with a cumulative strain larger than 1) are illustrated

833 in dark blue. a Case with the random seed number $=1$. $\mathbf{b}$ Case with the random seed 834 number $=3$.

835 Fig. 6 Results at 3 Myr for numerical simulations with a single preexisting fault zone.

836 The preexisting fault (PF) and the newly formed faults (markers with a cumulative

837 strain larger than 1 ) are illustrated in dark blue. The weakened friction coefficient $\mu_{w}$ is $838 \sim 0.5$ (weakened friction angle $\phi_{w}=30^{\circ}$ ). a Case with a dip angle of $15^{\circ} . \mathbf{b}$ Case with a 
840 Fig. 7 Effect of different weakened friction coefficients $\mu_{w}$ on the activity of a

841 preexisting fault with a dip angle of $60^{\circ}$. a Case with $\mu_{w}=\sim 0.4$ (weakened friction

842 angle $\left.\phi_{w}=24^{\circ}\right)$. b Case with $\mu_{w}=\sim 0.3\left(\phi_{w}=17^{\circ}\right)$. The preexisting fault (PF) and newly

843 formed faults (markers with a cumulative strain larger than 1) are illustrated in dark

844 blue.

845 Fig. 8 Results of the numerical simulation for a case with two preexisting fault zones

846 with dip angles of $40^{\circ}$ and $30^{\circ}$, corresponding to the Uemachi and Ikoma faults in the

847 Osaka Plain, respectively. a The initial model geometry and time evolution. The

848 epicenter of the 2018 northern Osaka earthquake (Kato and Ueda 2019), located 12

$849 \mathrm{~km}$ beneath the surface position $14 \mathrm{~km}$ from the Uemachi fault, is indicated by a star.

850 The lower panels show a close up view of a $60 \mathrm{~km} \times 10 \mathrm{~km}$ domain including the

851 western and eastern weak zones. The preexisting faults and newly formed faults

852 (markers with a cumulative strain larger than 1) are illustrated in dark blue. b Time

853 evolution of the vertical displacement rates along the western and eastern faults. c

854 Time evolution of the sedimentation rates near the Uemachi Upland (i.e., at the 
location of the OD-9 core site) and the Onchi River (i.e., at the location of the OD-3

856 core site). The imposed sedimentation rates at the location of the OD-1 core site are

857 also shown.

858 Fig. 9 Effect of changing the dip angle of the western fault (i.e., the Uemachi fault) on

859 the development of the geologic structures. a The initial geometry (upper), final

860 geometry (middle), and close up of the final geometry (lower) of the linear case with a

861 dip angle of $30^{\circ}$. b The initial geometry (upper), final geometry (middle), and close up

862 of the final geometry (lower) of the curved case. c The initial geometry (upper), final

863 geometry (middle), and close up of the final geometry (lower) of the more curved case.

864 The preexisting faults and newly formed faults (markers with a cumulative strain

865 larger than 1) are illustrated in dark blue. The epicenter of the 2018 northern Osaka

866 earthquake (Kato and Ueda 2019), located $12 \mathrm{~km}$ beneath the surface position $14 \mathrm{~km}$

867 from the Uemachi fault, is indicated by a star in the panels showing the result at 3 Myr.

$868 \mathrm{~d}$ Time evolution of the vertical displacement rates along the western and eastern

869 faults for the curved case. e Time evolution of the sedimentation rates near the

870 Uemachi Upland (i.e., at the location of the OD-9 core site) and the Onchi River (i.e., at 
871 the location of the OD-3 core site) for the curved case. The imposed sedimentation

872 rates at the location of the OD-1 core site are also shown.

873 Fig. 10 Results of the numerical simulations for previously proposed fault geometries.

874 a The initial geometry (upper), final geometry (middle), and close up of the final

875 geometry (lower) for the fault geometry of Ishiyama (2003) with a weakened friction

876 coefficient $\mu_{w}$ of $\sim 0.3$ (weakened friction angle $\phi_{w}=17^{\circ}$ ). b The initial geometry

877 (upper), final geometry (middle), and close up of the final geometry (lower) for the

878 fault geometry of Sato et al. (2009) with $\mu_{w}=\sim 0.4\left(\phi_{w}=24^{\circ}\right)$. The preexisting faults

879 and newly formed faults (markers with a cumulative strain larger than 1) are illustrated

880 in dark blue. UmF and IkF represent the surface positions of the Uemachi and Ikoma

881 faults, respectively. 


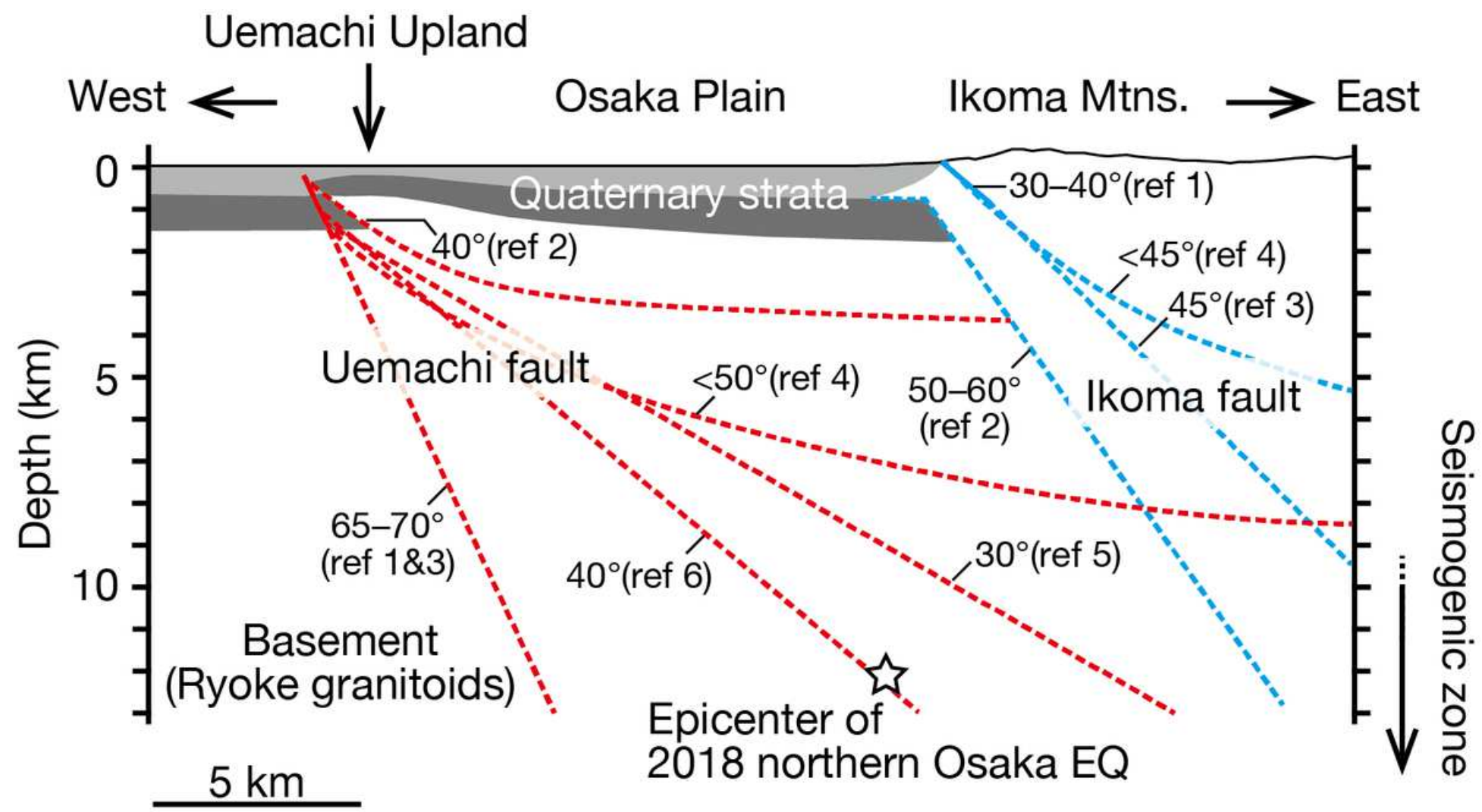

Figure 1

Figure 1

Summary of the inferred geometries of the Uemachi and Ikoma faults in the Osaka Plain illustrated on a schematic geological cross section (modified partially from Ishiyama 2003). Here, references 1, 2, 3, 4, 5 and 6 correspond to Headquarters for Earthquake Research Promotion of MEXT $(2001,2004)$, Ishiyama (2003), Director General for Disaster Management (2006), Sato et al. (2009), Iwasaki (2016) and Kato and Ueda (2016), respectively. The epicenter of the 2018 northern Osaka earthquake (EQ) proposed by Kato and Ueda (2019), located $12 \mathrm{~km}$ beneath the surface position $14 \mathrm{~km}$ from the Uemachi fault, is indicated by a star. 
a
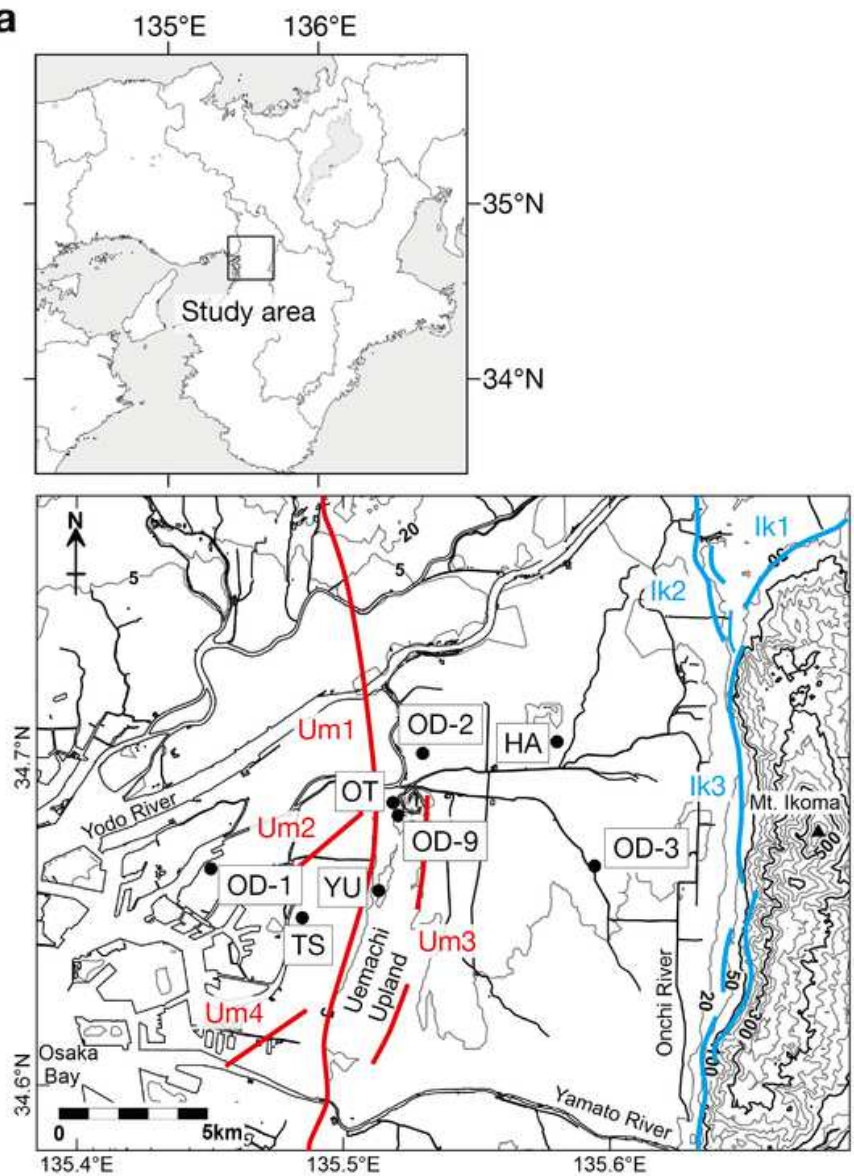

$900-$

b

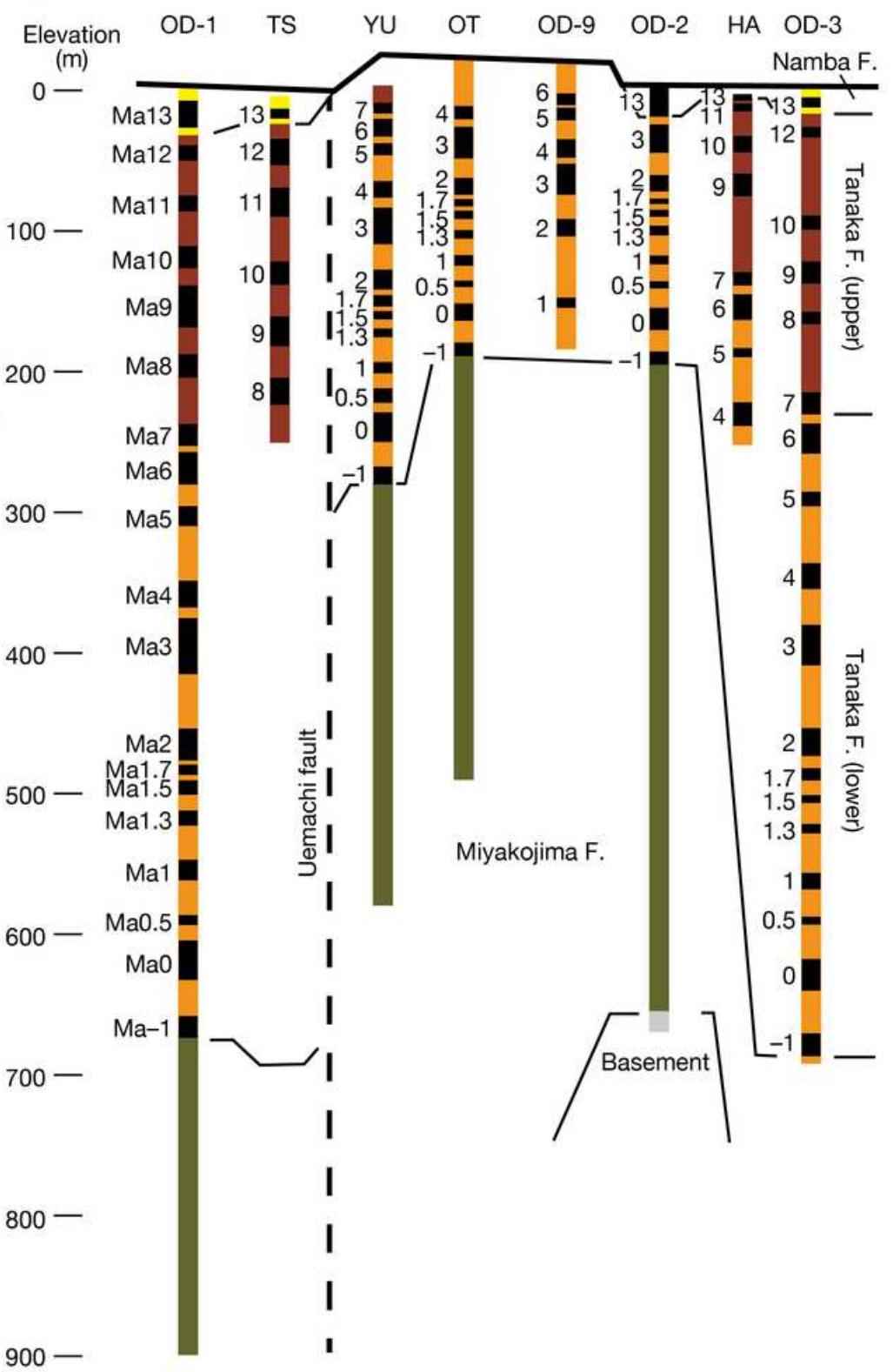

Figure 2

\section{Figure 2}

a Locations of the drilling sites on the Osaka Plain referred to in this study. Faults and flexures of the Uemachi fault zone include the Uemachi fault (Um1), Sakuragawa flexure (Um2), Nagai fault (Um3), and Suminoe flexure (Um4), and those of the Ikoma fault zone include the Katano fault (Ik1), Hirakata fault (Ik2), and Ikoma fault (Ik3) (Headquarters for Earthquake Research Promotion of MEXT 2001, 2004). The inset indicates the location of the study area. b Columnar sections of the OD-1, TS, YU, OD-9, OT, OD-2, HA, and OD-3 drilling cores (partially modified from Uchiyama et al. (2001)). 


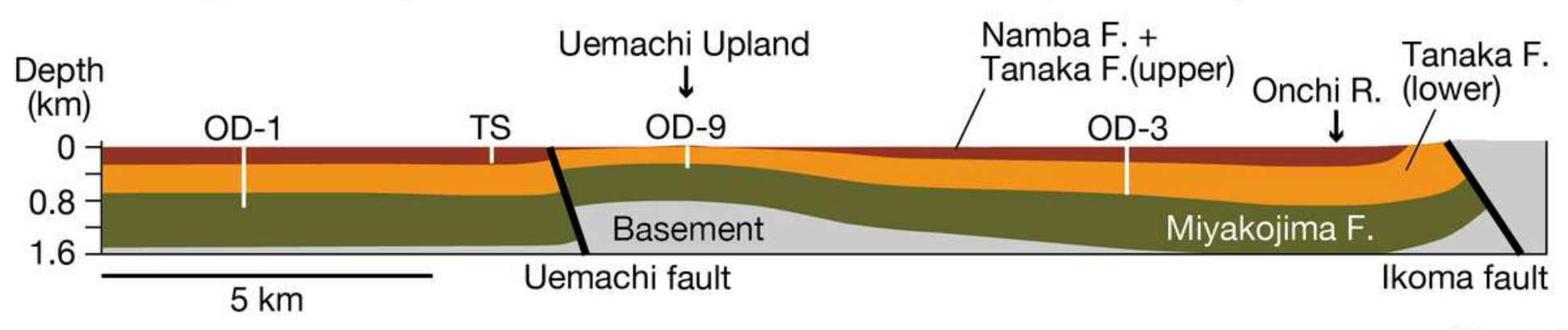

Figure 3

Figure 3

Schematic E-W geological section through the Osaka Plain (Uchiyama et al. 2001).

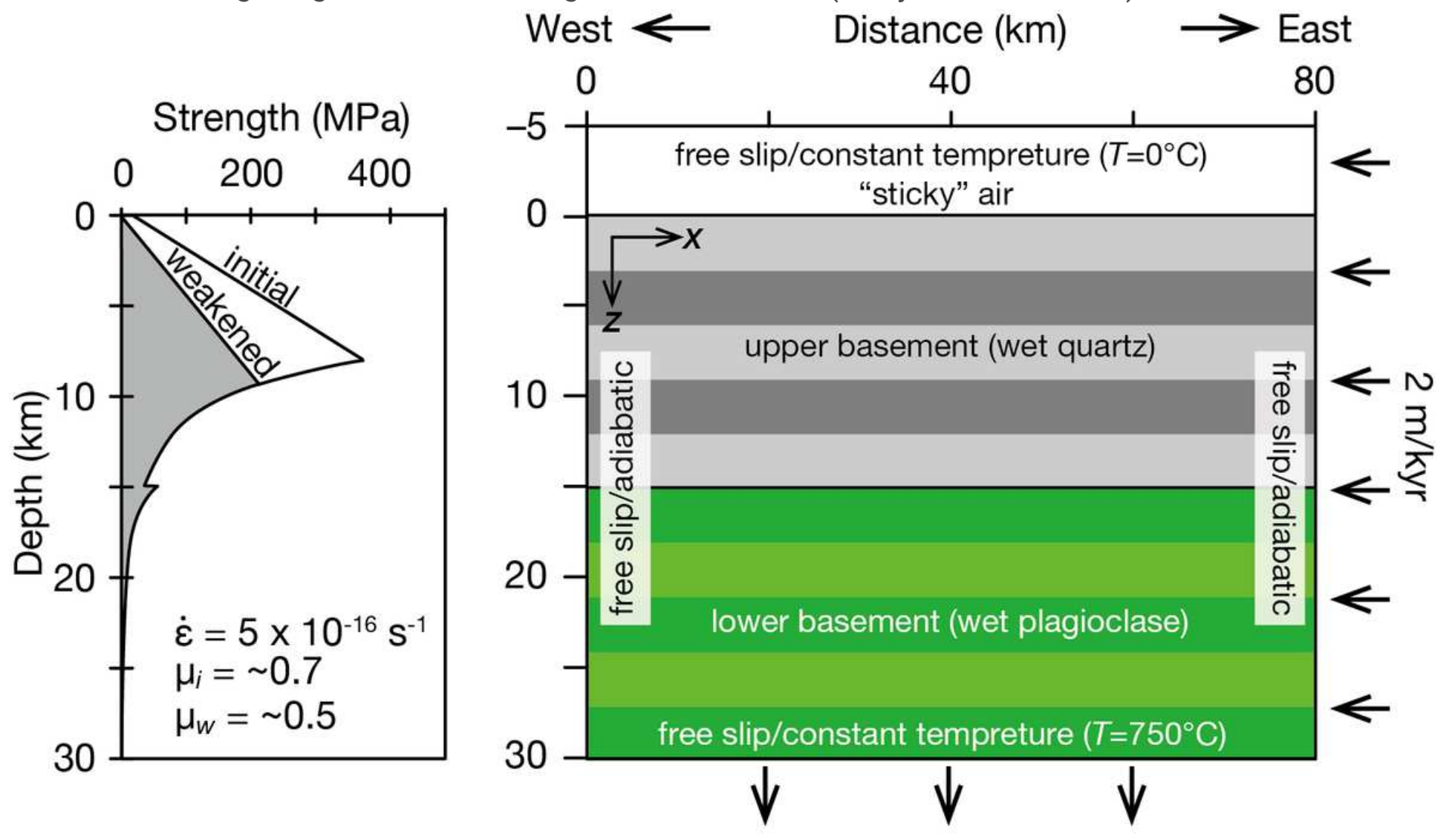

Figure 4

\section{Figure 4}

Model geometry and boundary conditions. The inset shows the crustal strength profile at the initial state in the numerical model. $\varepsilon \nabla, \mu \mathrm{i}$, and $\mu \mathrm{w}$ are the strain rate, the initial friction coefficient, and the weakened friction coefficient, respectively. A changing downward velocity (from $0.88 \mathrm{~m} / \mathrm{kyr}$ at $0 \mathrm{Myr}$ to $1.02 \mathrm{~m} / \mathrm{kyr}$ at $3 \mathrm{Myr}$ ) is applied at the bottom boundary. 

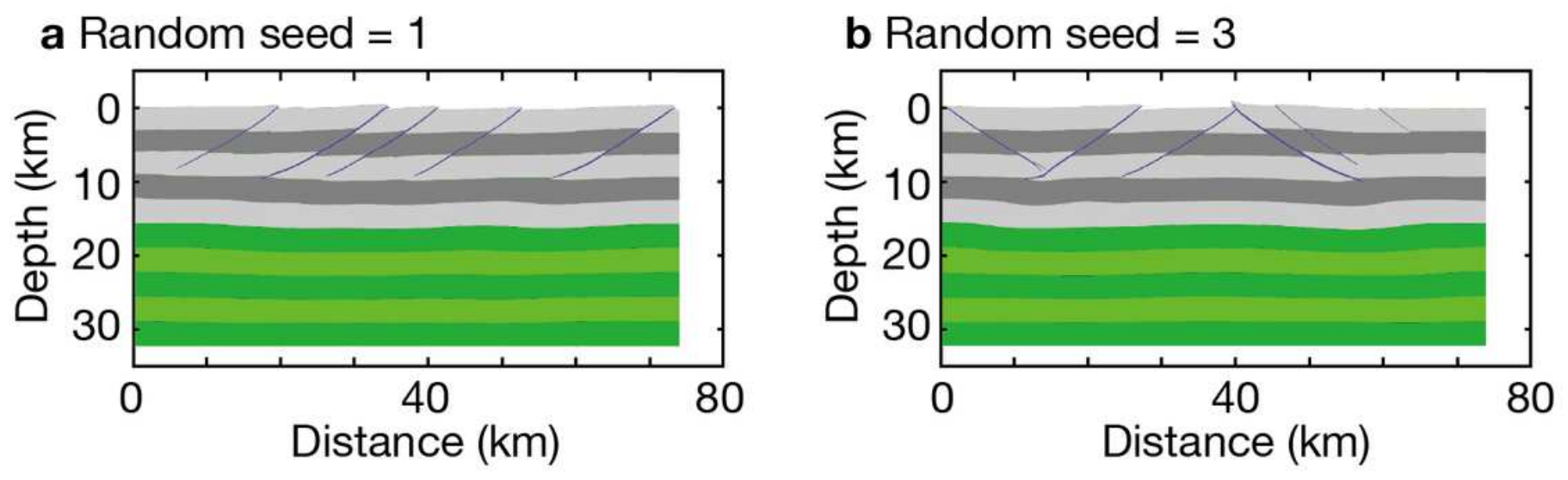

Figure 5

Figure 5

Results at 3 Myr for the numerical simulations with no preexisting fault zone. The newly formed faults (markers with a cumulative strain larger than 1) are illustrated in dark blue. a Case with the random seed number $=1 . b$ Case with the random seed number $=3$. 

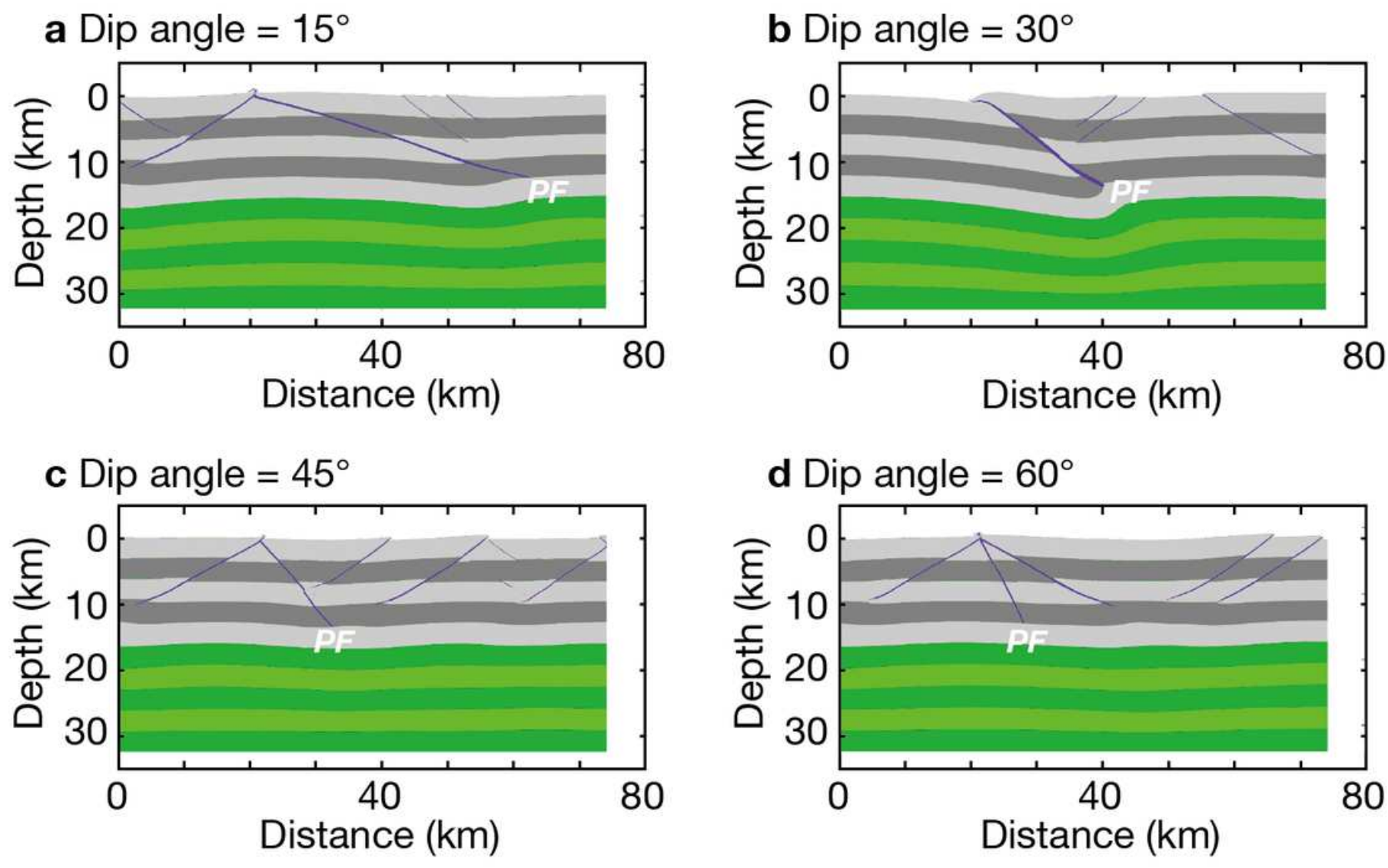

Figure 6

\section{Figure 6}

Results at 3 Myr for numerical simulations with a single preexisting fault zone. The preexisting fault (PF) and the newly formed faults (markers with a cumulative strain larger than 1) are illustrated in dark blue. The weakened friction coefficient $\mu \mathrm{w}$ is $\sim 0.5$ (weakened friction angle $\varphi w=30^{\circ}$ ). a Case with a dip angle of $15^{\circ}$. b Case with a dip angle of $30^{\circ}$. c Case with a dip angle of $45^{\circ}$. d Case with a dip angle of $60^{\circ}$. 

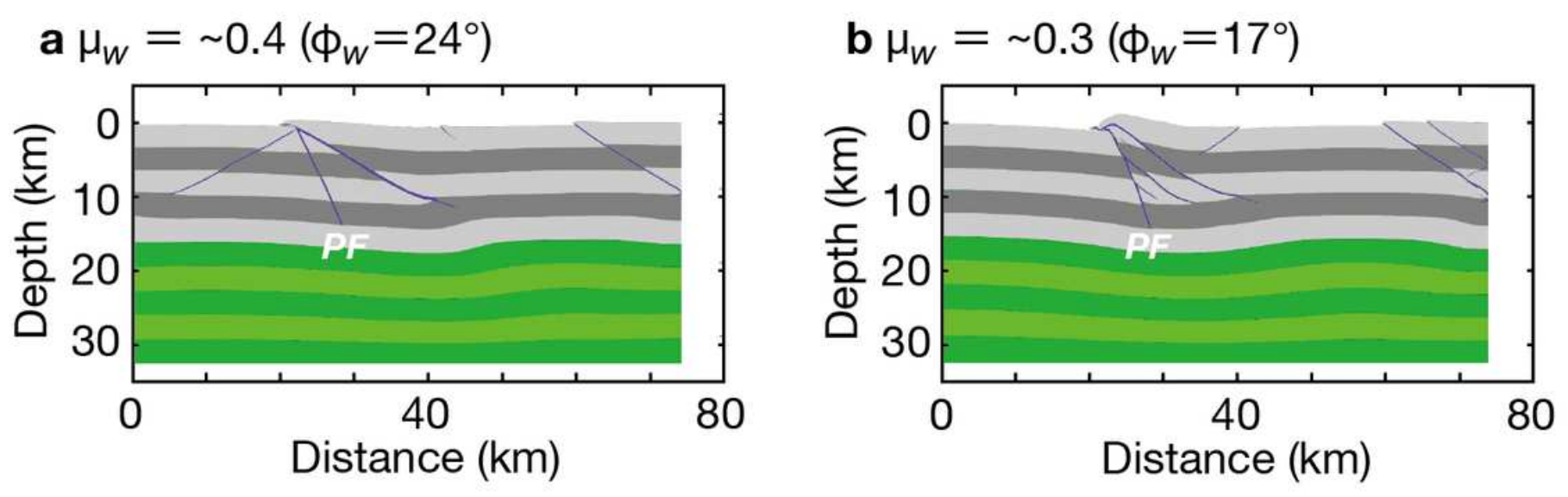

Figure 7

\section{Figure 7}

Effect of different weakened friction coefficients $\mu \mathrm{w}$ on the activity of a preexisting fault with a dip angle of $60^{\circ}$. a Case with $\mu \mathrm{w}=\sim 0.4$ (weakened friction angle $\left.\varphi w=24^{\circ}\right)$. b Case with $\mu \mathrm{w}=\sim 0.3\left(\varphi w=17^{\circ}\right)$. The preexisting fault (PF) and newly formed faults (markers with a cumulative strain larger than 1 ) are illustrated in dark blue.
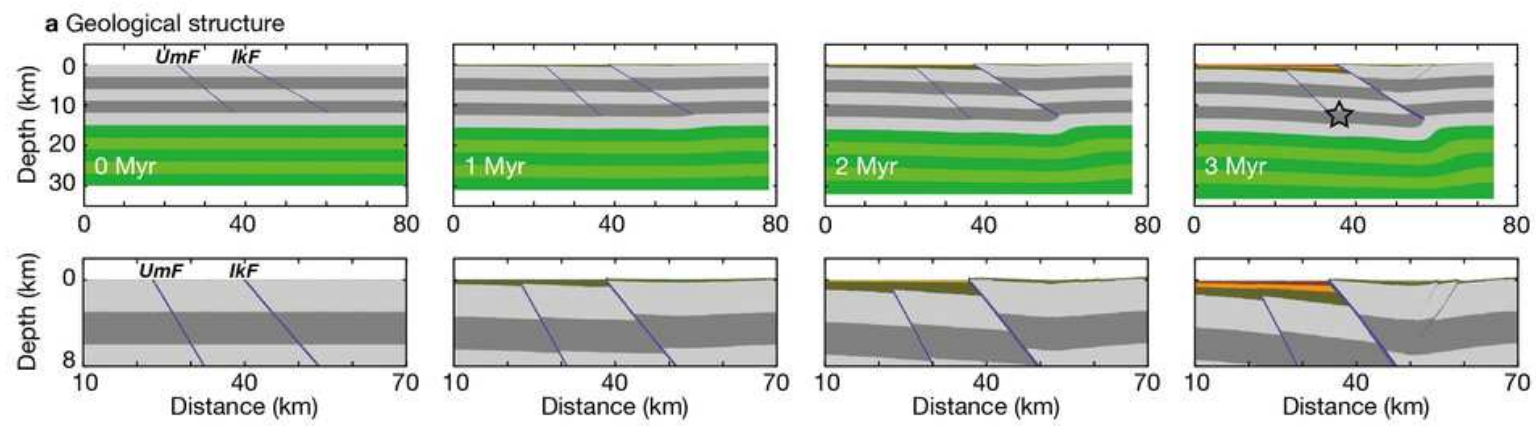

uppermost sediment (= upper Tanaka F.+Namba F.)
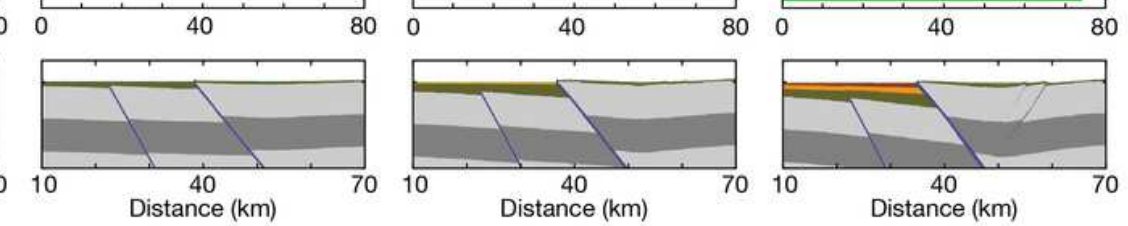

upper sediment (= lower Tanaka F.)
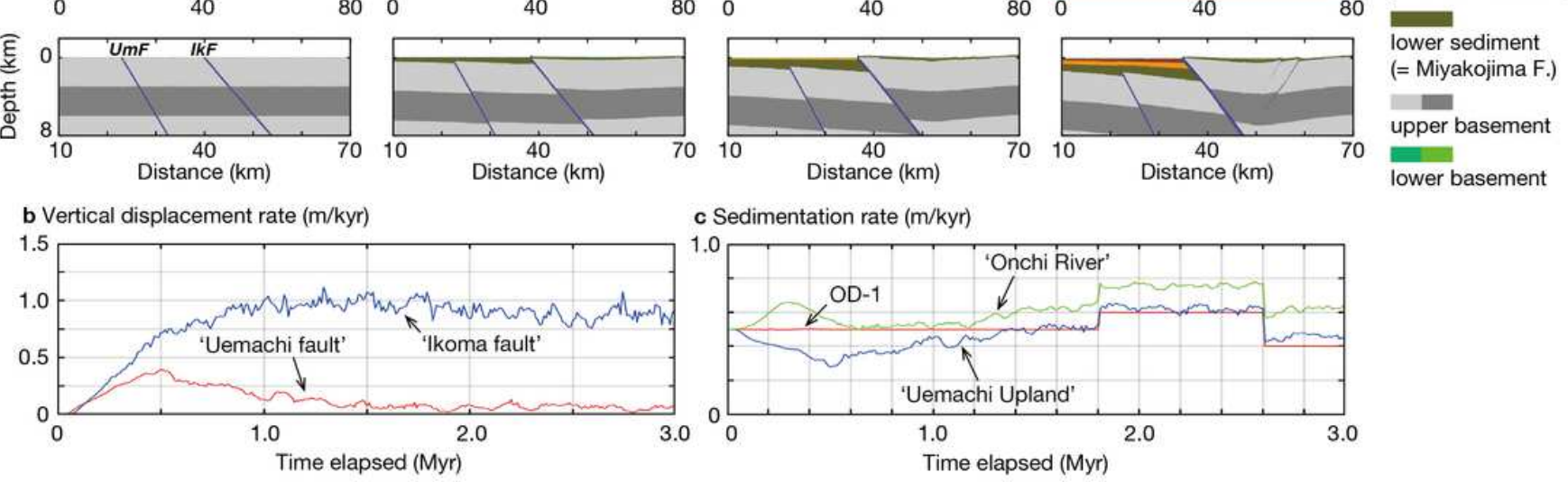

lower basement

Figure 8

\section{Figure 8}

Results of the numerical simulation for a case with two preexisting fault zones with dip angles of $40^{\circ}$ and $30^{\circ}$, corresponding to the Uemachi and Ikoma faults in the Osaka Plain, respectively. a The initial model geometry and time evolution. The epicenter of the 2018 northern Osaka earthquake (Kato and Ueda 
2019), located $12 \mathrm{~km}$ beneath the surface position $14 \mathrm{~km}$ from the Uemachi fault, is indicated by a star. The lower panels show a close up view of a $60 \mathrm{~km} \times 10 \mathrm{~km}$ domain including the western and eastern weak zones. The preexisting faults and newly formed faults (markers with a cumulative strain larger than 1) are illustrated in dark blue. b Time evolution of the vertical displacement rates along the western and eastern faults. c Time evolution of the sedimentation rates near the Uemachi Upland (i.e., at the location of the OD-9 core site) and the Onchi River (i.e., at the location of the OD-3 core site). The imposed sedimentation rates at the location of the OD-1 core site are also shown.
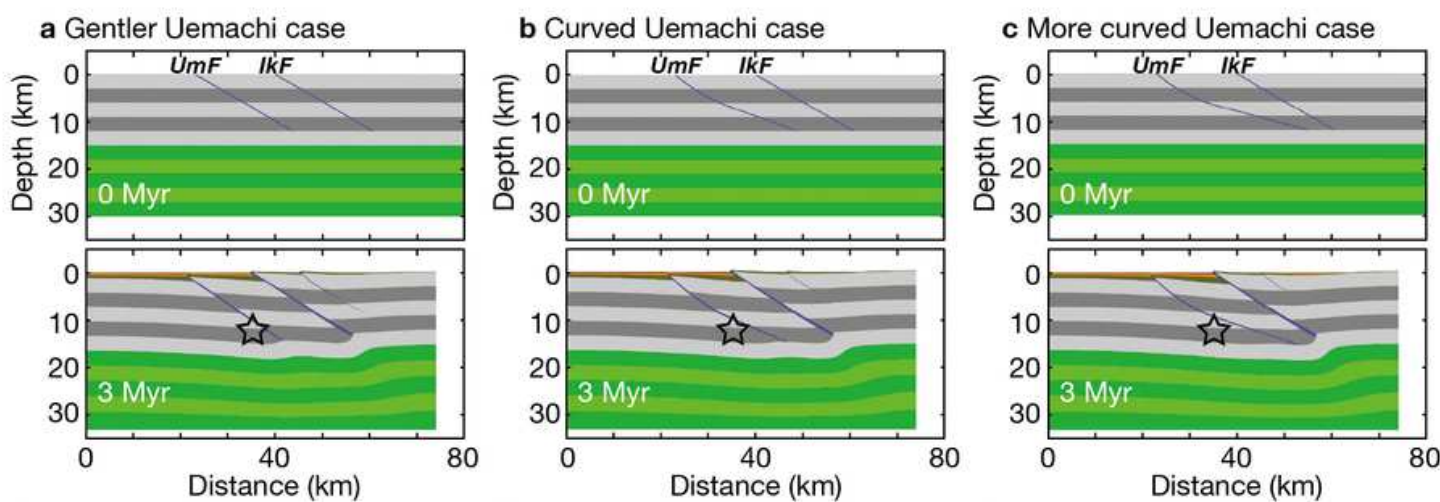

uppermost sediment (= upper Tanaka F.+Namba F.)
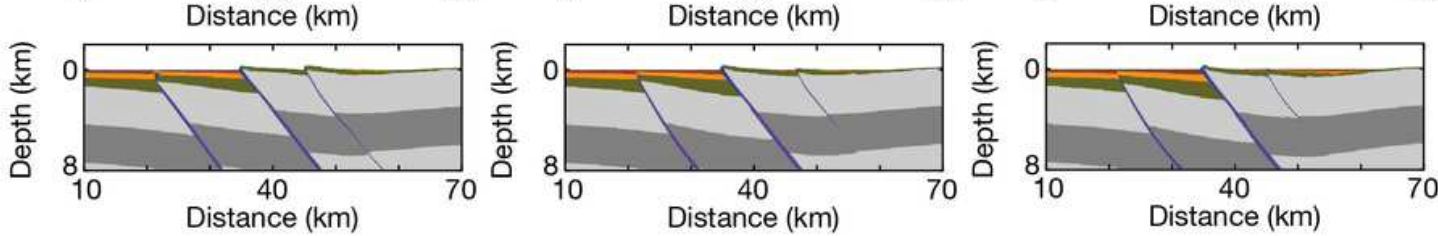

upper sediment (= lower Tanaka F.)

lower sediment (= Miyakojima F.)

in upper basement lower basement

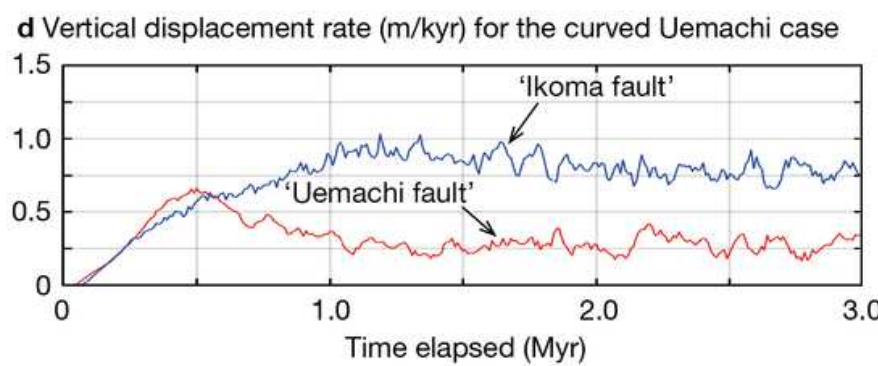

e Sedimentation rate $(\mathrm{m} / \mathrm{kyr})$ for the curved Uemachi case

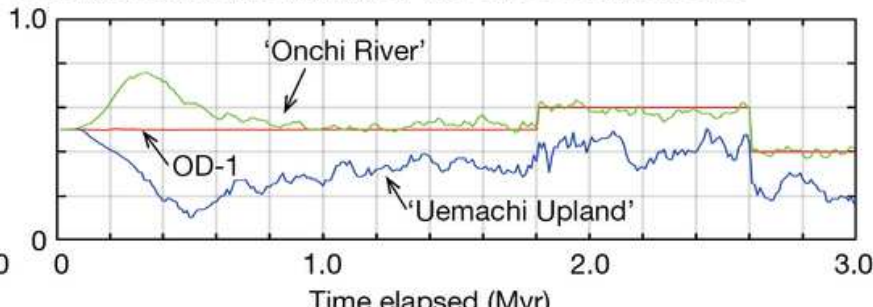

Figure 9

\section{Figure 9}

Effect of changing the dip angle of the western fault (i.e., the Uemachi fault) on the development of the geologic structures. a The initial geometry (upper), final geometry (middle), and close up of the final geometry (lower) of the linear case with a dip angle of $30^{\circ}$. b The initial geometry (upper), final geometry (middle), and close up of the final geometry (lower) of the curved case. c The initial geometry (upper), final geometry (middle), and close up of the final geometry (lower) of the more curved case. The preexisting faults and newly formed faults (markers with a cumulative strain larger than 1 ) are illustrated in dark blue. The epicenter of the 2018 northern Osaka earthquake (Kato and Ueda 2019), located $12 \mathrm{~km}$ beneath the surface position $14 \mathrm{~km}$ from the Uemachi fault, is indicated by a star in the panels showing the result at 3 Myr. $d$ Time evolution of the vertical displacement rates along the western and eastern faults for the curved case. e Time evolution of the sedimentation rates near the Uemachi Upland (i.e., at 
the location of the OD-9 core site) and the Onchi River (i.e., at the location of the OD-3 core site) for the curved case. The imposed sedimentation rates at the location of the OD-1 core site are also shown.

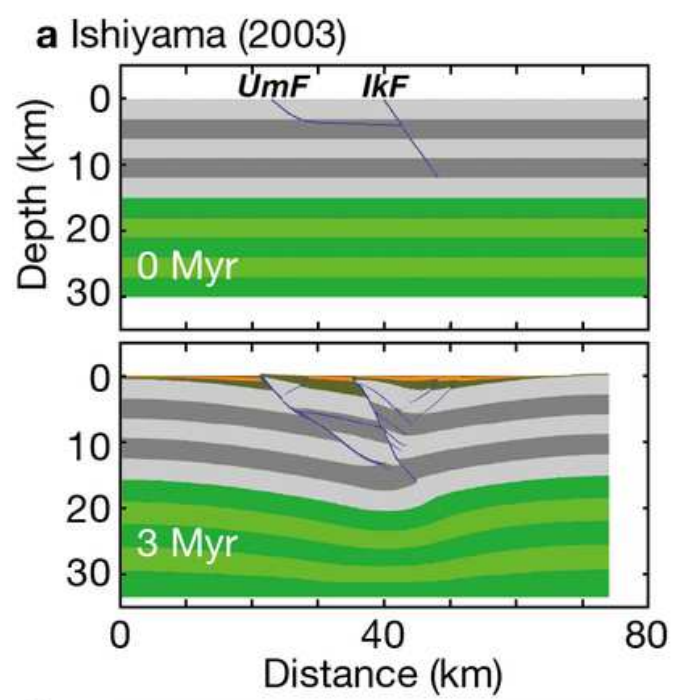

b Sato et al. (2009)
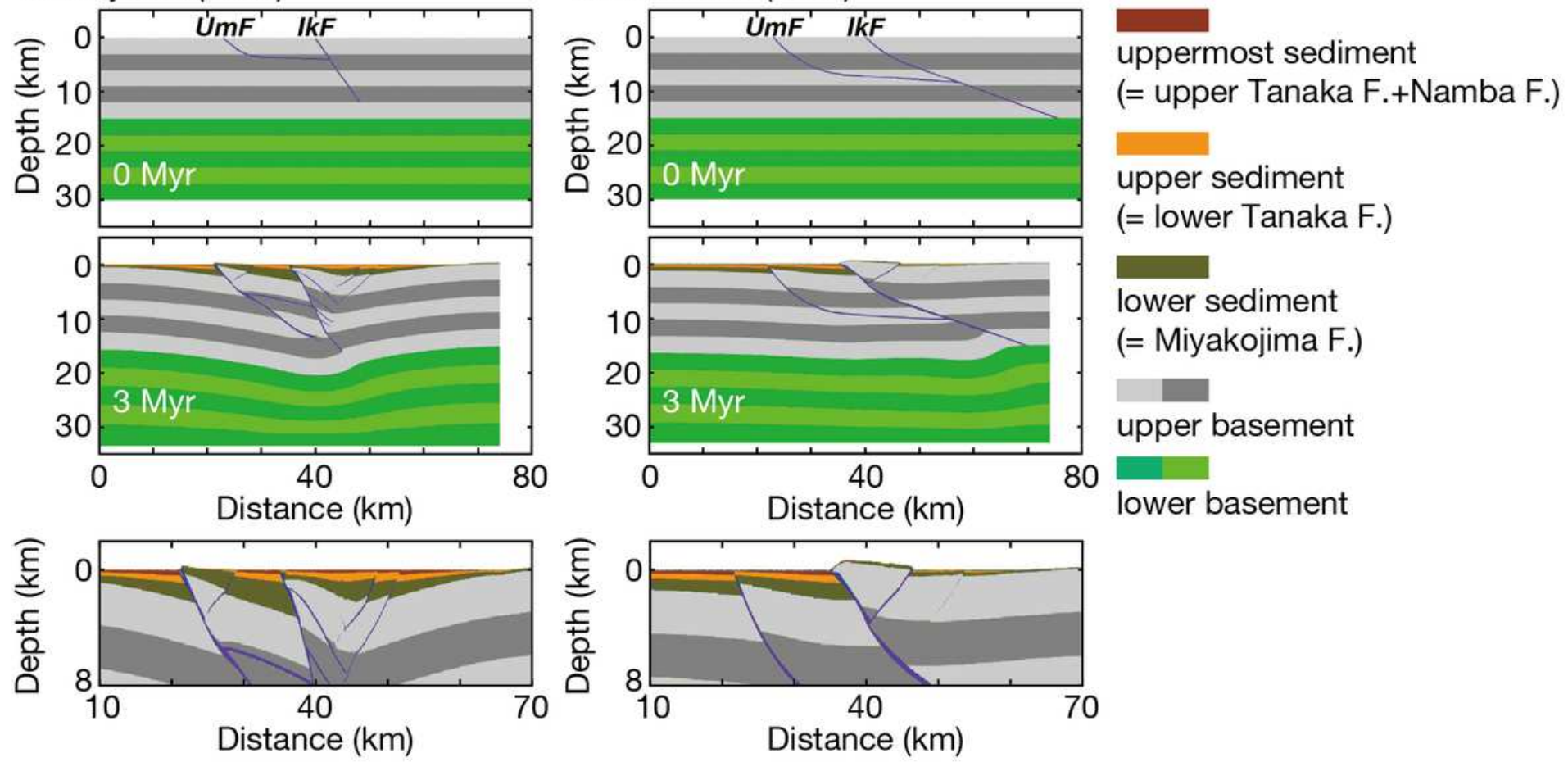

Figure 10

\section{Figure 10}

Results of the numerical simulations for previously proposed fault geometries. a The initial geometry (upper), final geometry (middle), and close up of the final geometry (lower) for the fault geometry of Ishiyama (2003) with a weakened friction coefficient $\mu \mathrm{w}$ of $\sim 0.3$ (weakened friction angle $\varphi w=17^{\circ}$ ). $\mathrm{b}$ The initial geometry (upper), final geometry (middle), and close up of the final geometry (lower) for the fault geometry of Sato et al. (2009) with $\mu \mathrm{w}=\sim 0.4\left(\varphi \mathrm{w}=24^{\circ}\right)$. The preexisting faults and newly formed faults (markers with a cumulative strain larger than 1) are illustrated in dark blue. UmF and IkF represent the surface positions of the Uemachi and Ikoma faults, respectively.

\section{Supplementary Files}


This is a list of supplementary files associated with this preprint. Click to download.

- Table1.docx

- GraphicalAbstract.png

- Additionalfile1.docx 